Illinois State University

ISU ReD: Research and eData

Theses and Dissertations

$10-3-2015$

\title{
"Sing me a sad song and make me feel better": Exploring rewards related to liking familiar sad music
}

John D. Hogue

Illinois State University, jdhogue@hotmail.com

Follow this and additional works at: https://ir.library.illinoisstate.edu/etd

Part of the Music Commons, and the Psychology Commons

\section{Recommended Citation}

Hogue, John D., "'Sing me a sad song and make me feel better": Exploring rewards related to liking familiar sad music" (2015). Theses and Dissertations. 469.

https://ir.library.illinoisstate.edu/etd/469

This Thesis is brought to you for free and open access by ISU ReD: Research and eData. It has been accepted for inclusion in Theses and Dissertations by an authorized administrator of ISU ReD: Research and eData. For more information, please contact ISUReD@ilstu.edu. 


\title{
"SING ME A SAD SONG AND MAKE ME FEEL BETTER": EXPLORING REWARDS RELATED TO LIKING FAMILIAR SAD MUSIC
}

\author{
John D. Hogue
}

\section{Pages}

Hogue (2013) tested some of Levinson's (1997) theoretical ideas about why people like listening to songs that make them sad. Particularly, Hogue tested Levinson's ideas of communion, mediation, savoring feeling, and how absorption interacted with the songs to affect communion and the emotion. Hogue, however, did not use musical stimuli that were familiar to the participants, which is a precursor to Levinson's (1997) theory. This thesis retested Levinson's theory comparing familiar songs against unfamiliar songs and songs from another participant.

Data were collected from 82 participants. Each participant provided songs that induced happiness and songs that induced sadness. Participants listened to their selfselected songs (familiar), the self-selected songs from the prior participant, and songs that the experimenter chose for everyone to hear (unfamiliar songs). For each type of song, the participants listened to a song that induced happiness and a song that induced sadness. After listening to each song, the participants rated how much emotion (happiness and sadness) and how much satisfaction they had. They also rated how much they liked each 
song and how much they connected to each song. Also, some participants rated how much they could absorb themselves in music before listening to the songs, but others did so after listening to the songs.

Results showed that the participants connected with the familiar songs more than they did with the prior-participant and unfamiliar songs, but that they connected with the familiar songs that induced sadness equally as much as they did with the familiar songs that induced happiness. Sadness mediated the effect that the song on how much the participants connected to the song. Satisfaction predicted liking songs that induced sadness. Finally, absorption did not interact with the songs to influence inducing the emotion or how much they connected with the song.

These results supported Levinson's (1997) ideas of communion and the mediated process that the songs influence the emotion, which influences the amount of communion. It did not, however, completely support the idea that satisfaction lessened the severity of sadness on liking the song (savoring feeling) or the idea that absorption would affect the emotions and communion. These results did not support all of Hogue's (2013) findings, showing that people respond to familiar songs differently than they do to unfamiliar songs.

KEYWORDS: Absorption, Communion, Happy Songs, Liking, Sad Songs, Satisfaction. 
"SING ME A SAD SONG AND MAKE ME FEEL BETTER": EXPLORING REWARDS RELATED TO LIKING FAMILIAR SAD MUSIC

JOHN D. HOGUE

A Thesis Submitted in Partial

Fulfillment of the Requirements for the Degree of

MASTER OF MUSIC

School of Music

ILLINOIS STATE UNIVERSITY

2015 
(C) 2015 John D. Hogue 
"SING ME A SAD SONG AND MAKE ME FEEL BETTER": EXPLORING REWARDS RELATED TO LIKING FAMILIAR SAD MUSIC

JOHN D. HOGUE

COMMITTEE MEMBERS:

Andrea M Crimmins, Chair

Cindy R. Ropp

Jeffrey H. Kahn 


\section{ACKNOWLEDGMENTS}

This thesis would not have been possible without the overwhelming, encouraging support from my committee, Drs. Jef Kahn, Andrea Crimmins, and Cindy Ropp. Their guidance, support, and commitment to this project have been incredible. Humbly and gratefully, I thank them for their efforts in helping me complete this project.

J. D. H. 


\section{CONTENTS}

Page

ACKNOWLEDGMENTS $\quad$ i

CONTENTS $\quad$ ii

TABLES $\quad$ V

FIGURES

CHAPTER

I. INTRODUCTION

II. REVIEW OF THE LITERATURE

General Literature Review 2

Philosophical Background 2

Key Definitions $\quad 5$

Importance of Studying Familiar Music $\quad 6$

Using Self-selected Songs as Familiar Songs $\quad 7$

Research Questions and Hypotheses $\quad 9$

Do Songs that Induce Sadness Influence Communion? 10

Do the Evoked Emotions Mediate the Song's Effect of Influencing Communion? 11

Does Satisfaction Moderate the Evoked Emotions' Effect on Liking? 11

Does Absorbing Oneself into the Songs Moderate the Effect of the Songs on Inducing Emotion and Communion? 13

$\begin{array}{ll}\text { III. METHOD } & 16\end{array}$

$\begin{array}{ll}\text { Participants } & 16\end{array}$

$\begin{array}{lr}\text { Materials } & 17\end{array}$

$\begin{array}{ll}\text { Absorption } & 17\end{array}$ 
Liking

Communion 18

$\begin{array}{ll}\text { Emotions and Other Measures } & 18\end{array}$

$\begin{array}{ll}\text { Definitions of satisfaction } & 18\end{array}$

Unfamiliar song that induced happiness 19

Unfamiliar song that induced sadness 20

Prior-participant song that induced happiness 20

Prior-participant song that induced sadness 20

Familiar song that induced happiness 20

Familiar song that induced sadness 20

$\begin{array}{ll}\text { Musical Stimuli } & 21\end{array}$

Unfamiliar songs $\quad 21$

$\begin{array}{ll}\text { Familiar songs } & 21\end{array}$

$\begin{array}{ll}\text { Instruments } & 27\end{array}$

$\begin{array}{ll}\text { Design } & 27\end{array}$

$\begin{array}{ll}\text { Procedure } & 28\end{array}$

$\begin{array}{ll}\text { IV. RESULTS } & 30\end{array}$

$\begin{array}{ll}\text { Preliminary Results } & 30\end{array}$

$\begin{array}{ll}\text { Correlations } & 30\end{array}$

Familiarity Manipulation Check $\quad 32$

Emotion 33

Communion 38

Liking $\quad 40$

Absorption $\quad 42$

$\begin{array}{ll}\text { Primary Analyses } & 42\end{array}$

Is There a Difference in Communion among the Songs? 42

Do Happiness and Sadness Mediate the Song's Effect of Influencing Communion? 43

Happiness $\quad 44$

Sadness $\quad 46$

Does Satisfaction Moderate Evoked Happiness's and Sadness's Effect on Liking a Song? 
Happiness $\quad 48$

Sadness $\quad 48$

Is Absorption a Moderator in Inducing Emotion and Communion from the Songs?

Happiness $\quad 50$

Sadness $\quad 50$

Communion in songs that induced happiness $\quad 50$

Communion in songs that induced sadness $\quad 50$

V. DISCUSSION

Connection to the Hypotheses $\quad 52$

Do Songs that Induce Sadness Influence Communion? 52

Do the Evoked Emotions Mediate the Song's Effect on
Influencing Communion?

Does Satisfaction Moderate Evoked Emotions' Effect on Liking a Song? 54

Does Absorbing Oneself into the Songs Moderate the Effect of the Songs on Inducing Emotion and Communion? 56

Differences with Past Research $\quad 58$

Limitations $\quad 59$

$\begin{array}{ll}\text { Implications } & 59\end{array}$

Clinical Applications $\quad 59$

Future Research $\quad 60$

$\begin{array}{ll}\text { Conclusion } & 62\end{array}$

REFERENCES

$\begin{array}{lll}\text { APPENDIX A: } & \text { Demographics Questionnaire }\end{array}$

APPENDIX B: Absorption in Music Scale (AIMS) 70

APPENDIX C: Dependent Measures $\quad 76$

APPENDIX D: $\quad$ Emotion Response Questionnaire 78

APPENDIX E: Questions for the Songs Rater 79 


\section{TABLES}

Table $\quad$ Page

1. List of Songs that Induced Happiness 22

2. List of Songs that Induced Sadness 24

3. Counterbalancing Sets 28

4. Correlations Among the Unfamiliar Songs that Induced Happiness 30

5. Correlations Among the Unfamiliar Songs that Induced Sadness 30

6. Correlations Among the Prior-participant Songs that Induced Happiness 31

7. Correlations Among the Prior-participant Songs that Induced Sadness 31

8. Correlations Among the Familiar Songs that Induced Happiness 31

9. Correlations Among the Familiar Songs that Induced Sadness 32 


\section{FIGURES}

Figure $\quad$ Page

1. Hypothesis for the musical selections and emotional content on $\begin{array}{ll}\text { communion } & 10\end{array}$

2. Hypothesis for the mediation process 11

3. Hypothesis for savoring feeling 12

4. Hypothesis for the absorption and song selection interaction on influencing communion

5. Hypothesis for the absorption and song interaction on evoking emotions 15

6. Satisfaction defined as liking among all six songs 19

7. Familiarity manipulation check 33

8. Emotion evoked for each song type 34

9. Absorption placement by random assignment on overall evoked emotion 35

10. Song type on happiness and sadness 36

11. Song type by random assignment set on happiness 37

12. Song type by random assignment set on sadness 38

13. Song type on communion 39

14. Song type on liking 41

15. Familiarity on communion 43

16. Happiness by familiarity on communion 45

17. Sadness and limited familiarity on communion 46 
18. Sadness by satisfaction interaction on liking for unfamiliar songs 


\section{CHAPTER I \\ INTRODUCTION}

A paradox appears to exist when someone listens to music that makes him or her sad. Levinson (1997) proposed that listening to music that induces sadness could be a rewarding experience, and he described eight rewards. Hogue (2013) tested four of these rewards, but he used instrumental excerpts that were unfamiliar to the participants.

Because Levinson (1997) stated that familiarity is a precursor to achieving the rewards, Hogue's (2013) work alone is not sufficient to test Levinson's (1997) ideas. In fact, the more people are familiar with a song, the more likely they are to like it (North \& Hargreaves, 1995). Therefore, the purpose of this thesis was to replicate Hogue's (2013) study with songs that are familiar to the participants. 


\section{CHAPTER II}

\section{REVIEW OF THE LITERATURE \\ General Literature Review}

\section{Philosophical Background}

Levinson (1997) suggested that people like to listen to songs that induce sadness because they achieve a positive hedonic reward. Levinson detailed eight rewards in his work. The first reward was a mediated process, where the song created an emotion, which in turn created a nonmusical outcome. A much clearer and stronger grasp of the song was one example he provided as a nonmusical outcome. The second reward he presented was that of catharsis. He explained that the listener would allow him or herself to experience a strong negative emotion, such as grief, which would allow the listener to remove real-life grief, leading to increased mental health.

Levinson also discussed three emotional benefits of listening to songs that induce sadness. He called the first emotional benefit "savoring feeling" (p. 232), which he defined as when a person's satisfaction while listening to the song reduces the effect of sadness on liking the song. In other words, someone with low sadness but higher satisfaction would like the song more than someone with high sadness and low satisfaction. If the satisfaction made the sadness palatable, then the listener would increase his or her liking of the song that induced sadness. The second emotional benefit was called "emotional understanding" (p. 232), which is when the listener would explore 
the evoked emotion to understand it better. The third emotional benefit was called "emotional practice" (p. 233), which was when the listener used the song to practice different emotions. This emotional practice provided a safe place for the listener to rehearse the emotional response to prepare for a real life situation.

Finally, Levinson proposed three absorption benefits. Absorption is the listener's ability to put oneself into the stimulus while ignoring and separating oneself from reality (Tellegen \& Atkinson, 1974). The first absorption benefit was called "emotional resolution" (p. 235), which he defined as when the listener intensifies his or her emotional response to the song that induces sadness while absorbing his or herself into the song. This emotional increase could lead to an understanding of how to resolve such an intense emotion and is more pronounced in negative emotions than in positive emotions. The second absorption benefit was called "expressive potency" (p. 235), which was defined as when the listener feels the emotion evoked from the music as if it is a genuine emotion. This phenomenon, according to Levinson, occurs when the listener absorbs him or herself in to the song, and once the listener achieves this state of genuine emotion, the listener is filled with satisfaction. The third absorption benefit and last of all of Levinson's rewards is called "emotional communion" (p. 236), which was defined as "[t]he sense of intimate contact with the mind or soul of another, the sense that one is clearly not alone in the universe" (p.236). Essentially, the listener connects with the song and its composer, which mitigates the negative consequences of the negative emotion. Levinson stated that this last reward could potentially exist in songs that induce happiness and sadness. 
Hogue (2013) experimentally tested four of Levinson's (1997) rewards. In the Hogue (2013) study, each participant listened to three unfamiliar instrumental musical excerpts: one that induced sadness, one that induced happiness, and one that was neutral. Additionally, half of the participants completed a measure of absorption in music before listening to the musical excerpts and the other half completed the measure after listening to the musical excerpts. The results did not support Levinson's ideas of emotional communion, the mediated process of music inducing emotions and the emotions influencing a nonmusical outcome, or emotional potency. Savoring feeling, however, was supported. Statistically speaking, there were no significant differences in communion between the three excerpts. Happiness mediated the effect of the song on influencing communion but sadness did not, and higher absorption scores did not predict differing amounts of emotional strength among the songs. For savoring feeling, liking the song increased when sadness decreased if the listener had a high amount of satisfaction but not for average or low amounts of satisfaction.

Even though Hogue empirically tested Levinson's (1997) theory, Hogue (2013) failed to consider one of Levinson's (1997) precursors. Levinson's first precursor argued that before a song could evoke a strong emotion in the listener, the listener must be familiar enough with the work for the procession of the song to be internal but not so familiar that the listener would be bored with it. The second precursor argued that the listener must pay sole attention to the song while ignoring the outside world. The third precursor argued that the listener must be "willing to identify with the music, to put oneself in its shoes. One must allow oneself to be moved in a receptive manner by the emotion one hears, as opposed to merely noting or even marveling at it" (p. 228). Hogue 
(2013) accounted for the second two precursors by including a measure of absorption in music and by forcing the participant to listen to one musical excerpt at a time. Hogue failed, however, to account for the familiarity precursor because he only used unfamiliar instrumental excerpts. Therefore, the purpose of the current experiment was to replicate Hogue's work with music that was familiar to the participants.

\section{Key Definitions}

For this experiment, communion was considered a cognitive-emotional nonmusical outcome. It was the listener's ability to connect with the song and not feel alone.

Absorption was the listener's ability to place him or herself into the song completely while ignoring outside stimuli. This ability was considered to be a personality trait. For the purposes of this experiment, absorption was the ability of the listener to place him or herself completely into the songs, specifically.

Liking was measured based on how much the listener needed the song. It was also measure based on how much he or she actively pursued to listen to that song.

Satisfaction is typically regarded as a state of fulfillment up to but not beyond when a stimulus starts inducing negative effects, but many forms exist (Oliver, 2010). This study allowed the participants to provide their own definition of satisfaction. Qualitative summaries of these definitions can be found in the Method section.

Emotions are states of mind that have physiological consequences. The emotions in this experiment were happiness and sadness. Happiness was considered a pleasant state of bliss. Sadness was considered a state of sorrow. 


\section{Importance of Studying Familiar Music}

Research has shown that the more familiar participants were with a song, the more likely they were to like the song (North \& Hargreaves, 1995). Witvliet and Vrana (2007), however, found that people liked songs with a positive valence more than songs with a negative valence, and that this difference increased as exposure increased. In other words, they disliked the songs with a negative valence but liked the songs with a positive valence during the last listening trial. For the effect of exposure on emotions, Witvliet and Vrana also found that the more exposure participants had to a song with a negative valence, the stronger their negative emotions were and they were less likely to rate the song as pleasant. This effect did not occur in the songs with the positive valence.

Increasing familiarity through experimental manipulation of repetition has been shown to increase musical imagery (Byron \& Fowles, 2015). Research has also found positive correlations between familiarity and relaxing with the song (Tan, Yowler, Super, \& Fratianne, 2012) and between familiarity and a more intense emotional trigger (Ali \& Peynircioglu, 2010; Daynes, 2010). Pairing familiar songs with a series of numbers, however, did not increase the participants' memory of those numbers compared to unfamiliar songs (Silverman, 2010). A nonmanipulated increase in familiarity positively predicted an increase in choosing a song to hear and liking the songs (Ward, Goodman, \& Irwin, 2014).

These linear effects, however, are not the entire story because research on music also tends to show an inverted-U curve in the results. For example, Holbrook and Schindler (1989) found that liking popular music was highest when the participants were about 24 years old when the songs were popular. The younger and older the participants 
were when the songs were popular, the less they reported liking the songs. In a review of the literature, Bruner (1990) finds inverted-U curves involving tempo on mood, musical complexity on liking, and familiarity on liking.

To test further the inverted-U curve on familiarity on affect, Brentar, Neuendor, and Armstrong (1994) had people listen to four unfamiliar songs that sounded similar to pop and rock songs that would be played on the radio across four different exposure levels: $1,8,16$, and 24 exposures. They found that affect increased with each exposure but peaked and started to decrease between 8 and 18 exposures. Despite the nonlinear function of liking music based on familiarity, Ward et al. (2014) found that people would still choose to listen to songs even if they were "sick" of listening to the songs.

\section{Using Self-selected Songs as Familiar Songs}

Clearly, the past research has supported Levinson's (1997) idea of familiarity as a precursor to his theory, but to test his theory properly, songs that put the participants at the top of the inverted-U curve should be used. This procedure could be fulfilled by having the participants select their own music, as research has shown that familiarity predicts choosing to listen to a familiar song or an unfamiliar song: the more familiarity, the more likely the participants were to choose the familiar song (Ward et al., 2014).

Self-selected songs affect even nonmusical outcomes. Davis and Thaut (1989) had people listen to self-selected songs after asking the participants to sit quietly for 6,8 , or $10 \mathrm{~min}$. They found that state anxiety decreased after listening to the self-selected songs. Vascular blood flow scores were higher when the participants listened to their songs than during the no-music baseline, but heart rate, finger skin temperature, and muscular activity were similar. 
Thaut and Davis (1993) compared people listening to experimenter-given music, self-selected music, or silence against each other on changes in anxiety, relaxation, and depression. All songs were chosen for the specific purpose of increasing relaxation. Across all three conditions, the participants were more relaxed in the posttest than they were in the pretest. Anxiety decreased in both song conditions but not in the no-music condition. Depression did not change between the pre and posttests or between the three conditions. When Thaut and Davis asked their participants about coping strategies, they found that over $80 \%$ of the participants in the music conditions listed a music strategy and another, nonmusical strategy, but no one in the no-music condition listed a musical strategy. The research concluded by arguing "the music therapist should encourage patients to make individual musical choices based on personal preferences to enhance relaxation and reduce anxiety" (p. 221).

Blood and Zatorre (2001) had participants self-select a song that consistently gave them chills. Blood and Zatorre then had each participant listen to his or her self-selected song and to another participant's self-selected song. All participants picked music from the classical genre and listened to a 90 -s excerpt that included the section that evoked the chills. The other participant's self-selected song acted as a neutral stimulus, and each one was used only once, making sure to repurpose everyone's selection. Blood and Zatorre found that the measurement of the number of chills, the measurement of heart rate, the measurement from the electromyogram, and the measurement of respiration were higher in the self-selected songs compared to the experimenter-given songs. Measurements of electrodermal activity and skin temperature were not different between the two categories. They also found pleasantness and emotional intensity were higher than the 
intensity of the chills, which to them suggested that pleasantness and emotional intensity need to pass a certain threshold before the listener can experience chills.

Following Blood and Zatorre's (2001) procedure, Salimpoor et al. (2011) also had participants listen to self-selected pleasurable songs and to a song that was from another participant, yet matched participants' self-selected pleasurable songs. The participants reported having more pleasure and increased endogenous dopamine transmission in the self-selected songs than in the experimenter-given music. Before the emotional apex, the listeners' dopamine levels increased. This increase could indicate that "[a] sense of anticipation may arise through one's familiarity with the rules that underlie musical structure, such that listeners are anticipating the next note that may violate or confirm their expectations, in turn leading to emotional arousal, or alternatively it may arise through familiarity with a specific piece and knowing that a particularly pleasant section is coming up" (p. 262). Either way, these results support Levinson's (1997) first precursor of needing a familiar piece of music to evoke strong emotions, and that self-selected songs are familiar but not so familiar that the participant could not engage with it.

\section{Research Questions and Hypotheses}

As the purpose of this experiment was to replicate Hogue's (2013) experimental evaluation of Levinson (1997), this experiment used the same measures: a measure of absorption in music, a measure of liking the song, a measure of communion, and measures of satisfaction, happiness, and sadness. However, it paralleled the method used in Salimpoor et al. (2011) and Blood and Zatorre (2001). The only difference between this study and Hogue (2013) was that the participants listened to songs with which they 
were familiar (self-selected), songs that were not familiar (experiment-given), and songs from the prior participant.

\section{Do Songs that Induce Sadness Influence Communion?}

Levinson (1997) states that the reward of communion could occur in either songs that induce happiness or songs that induce sadness, but this statement was not supported in Hogue (2013). Because of the difference between self-selected songs and experimenter-given songs, however, Levinson's (1997) statement was still hypothesized, where the songs that induce happiness and sadness would have similar communion scores despite familiarity. However, communion scores would be highest for the familiar songs and lowest for the unfamiliar songs. See Figure 1 for a visual.

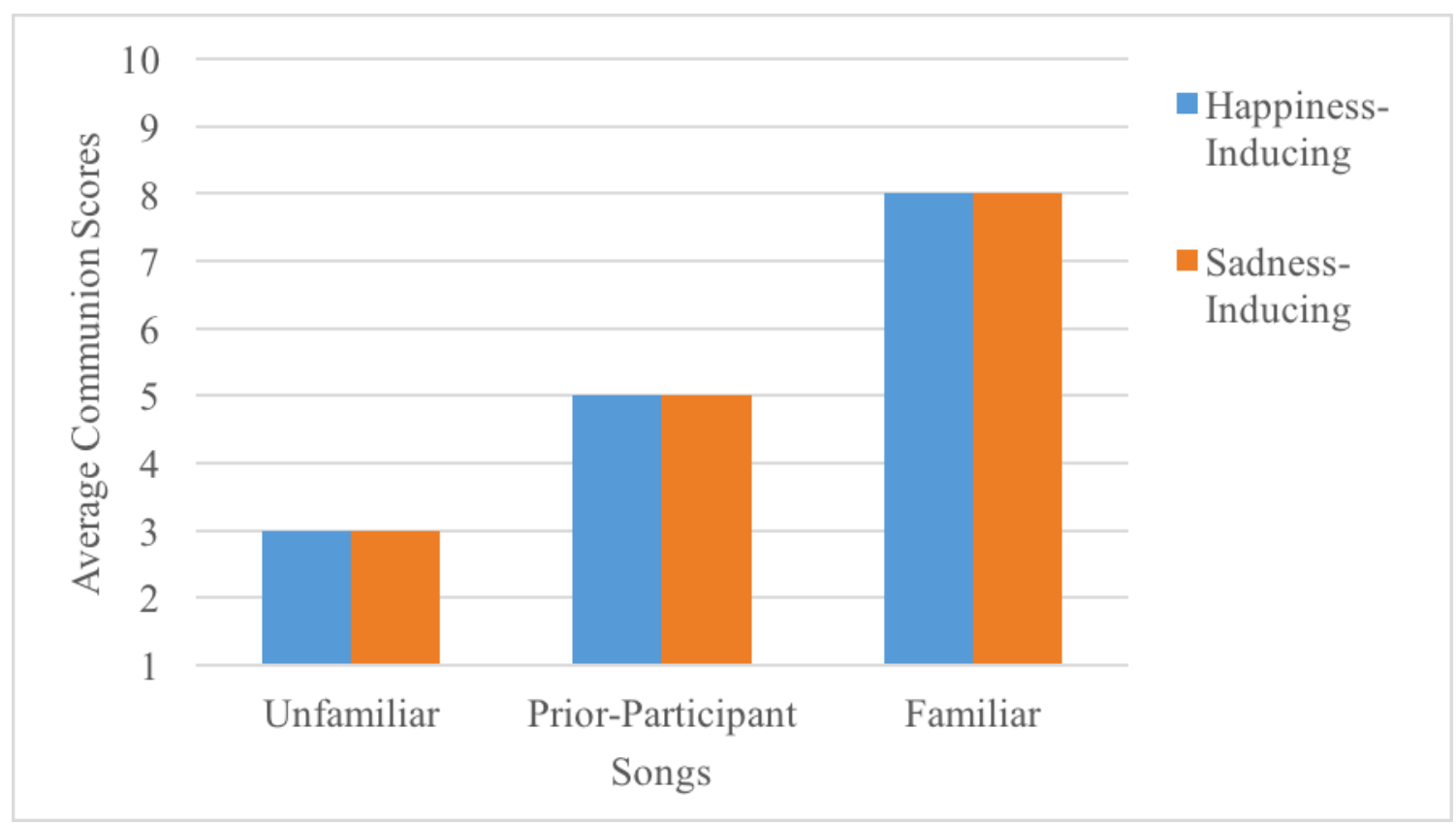

Figure 1. Hypothesis for the musical selections and emotional content on communion. Familiar songs would have higher communion scores than the less familiar songs. 


\section{Do the Evoked Emotions Mediate the Song's Effect of Influencing Communion?}

Levinson's (1997) first reward of listening to songs that induce sadness was the mediated process of the song inducing an emotion, and the emotion inducing the nonmusical outcome. Hogue (2013) supported the effect of happiness on communion but not the effect of sadness. Perhaps using familiar songs would increase the bond between the evoked emotion and the communion with the song. Because Levinson stated, "emotional response facilitates our grasp" (p. 230), it was expected that both happiness and sadness would increase communion the stronger they were felt. Therefore, the expected mediated process was that the songs that induced happiness and songs that induced sadness would influence happiness and sadness, respectively, and these emotions would positively predict communion. This process was only expected to work for familiar songs and not unfamiliar songs. See Figure 2 for a visual.

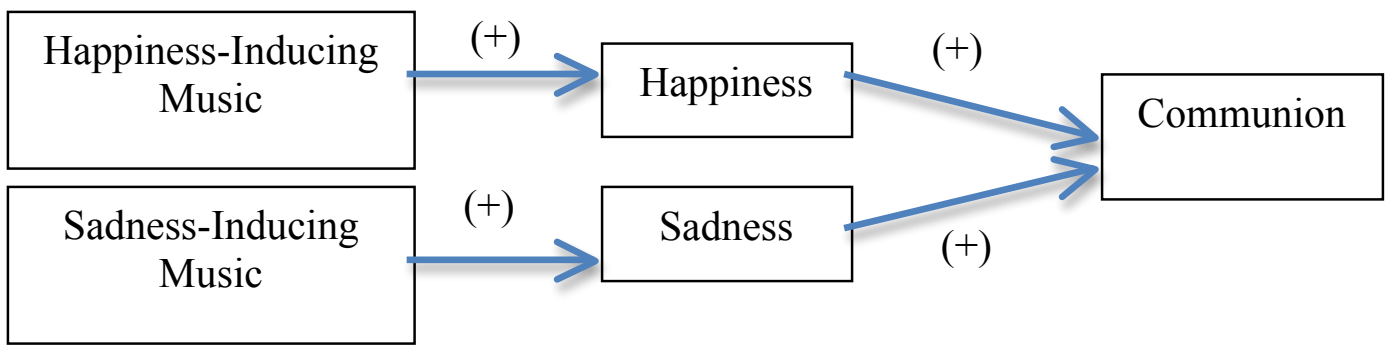

Figure 2. Hypothesis for the mediation process. Mediation path showing the song inducing an emotion and the emotions influencing the nonmusical outcome of communion.

\section{Does Satisfaction Moderate the Evoked Emotions' Effect on Liking?}

Levinson's reward of savoring feeling suggested that satisfaction plays an important role in liking a song that induces sadness. Hogue (2013) found that in the presence of satisfaction, happiness and sadness did not predict liking. He also found an 
interaction between satisfaction and sadness on liking, where the people with high satisfaction decreased their liking of the song as sadness increased, but the people with low satisfaction did not change their liking scores as a function of sadness. He did not, however, find a significant interaction between happiness and satisfaction.

For this reward, Levinson suggested that an increase in sadness would decrease liking, that an increase in satisfaction would increase liking, and that people low in sadness but high in satisfaction would like the song that induces sadness the most. People low in satisfaction would not change their liking of the song as sadness increased. As using self-selected songs would meet all of Levinson's precursors, his suggestions were still hypothesized in this study. Because Levinson suggested that the listener could enjoy the emotion if the emotion was not too intense, it was also hypothesized that happiness would have the same pattern of results as sadness. See Figure 3 for a visual example of the interaction.

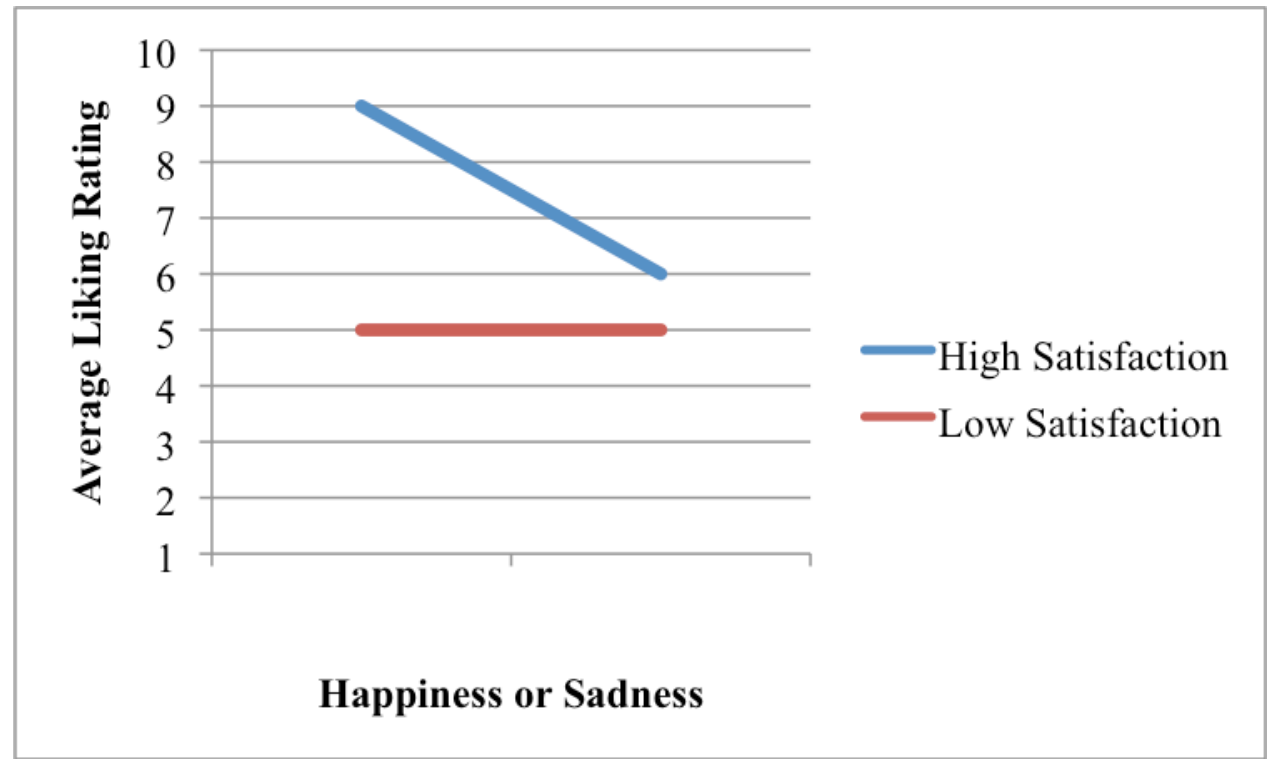

Figure 3. Hypothesis for savoring feeling. This figure shows that people high in satisfaction would decrease liking as the induced emotions decrease, but people low in satisfaction would not change their liking as the evoked emotions increase. 


\section{Does Absorbing Oneself into the Songs Moderate the Effect of the Songs on Inducing Emotion and Communion?}

As Levinson's reward of communion was listed as a benefit of absorption, the first

hypothesis alone was not sufficient enough to test this reward, especially considering that the Tellegen Absorption Scale did not predict changes in the ventral striatum while listening to self-selected pleasant music but a sub facet of absorption (self-forgetfulness) negatively predicted changes (Montag, Reuter, \& Axmacher, 2011). Levinson (1997) stated that communion would exist even when the emotional content of the song was positive or negative. Hogue's (2013) test of this hypothesis did not support Levinson (1997). If there were little emotional effect, however, then absorption would not play a strong role in inducing communion. Therefore, it was hypothesized that familiar songs would have higher communion scores than unfamiliar songs, and that people high in absorption would have higher communion scores than people low in communion. For the interaction, there would be a bigger difference in communion scores between low and high absorption in the familiar songs than there would be in the unfamiliar songs. See Figure 3 for a visual description. 


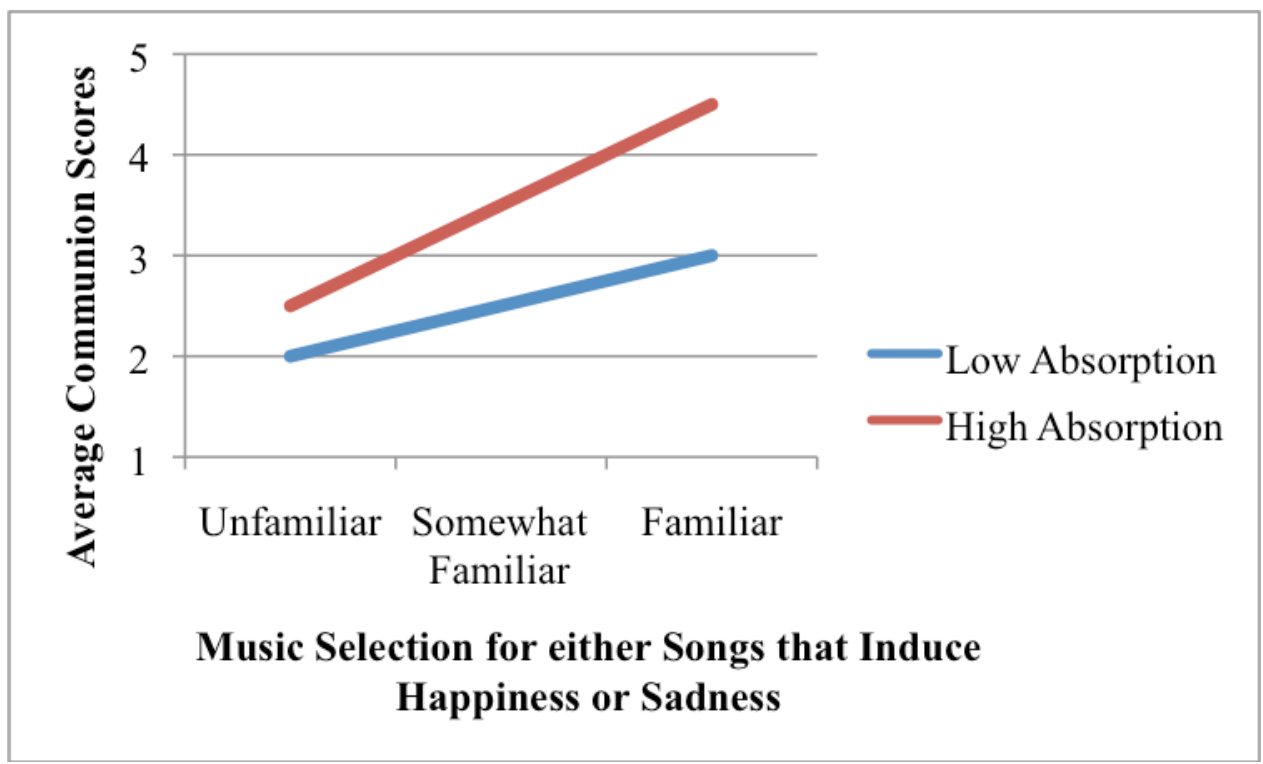

Figure 4. Hypothesis for the absorption and song selection interaction on influencing communion. This figure shows that communion was expected to increase more between the unfamiliar songs to the familiar songs for people high in absorption than communion will for people low in absorption.

Levinson's reward of emotional potency indicates that the more absorbed into the music the listener is, the stronger the emotional reactions. Absorption even positively correlated with items related to enjoying sad emotions and being able to garner psychological benefits (Garrido \& Schubert, 2013). Hogue's (2013) test of this reward, however, yielded results that were not statistically significant. For this thesis, listening to familiar songs was expected to induce stronger emotional reactions than listening to unfamiliar songs. Therefore, it was hypothesized that people with high absorption would have higher emotional reactions than people with low absorption scores. Finally, there would be a larger difference between people with high and low absorption in the familiar songs than there would be between the people with high and low absorption in the unfamiliar songs. 


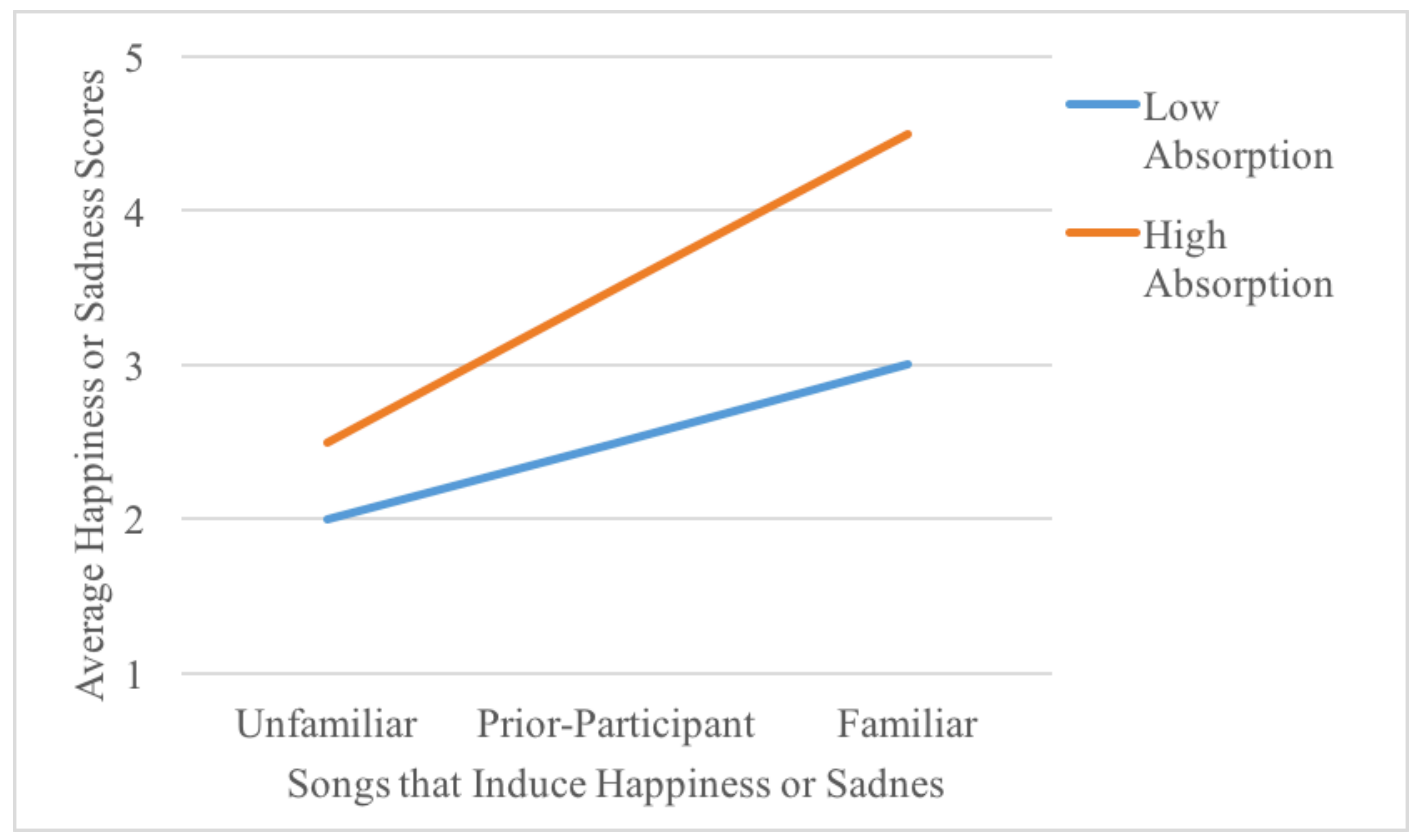

Figure 5. Hypothesis for the absorption and song interaction on evoking emotions. Emotion scores were expected to be less different for unfamiliar songs than for familiar songs. 


\section{CHAPTER III}

\section{METHOD}

\section{Participants}

Eighty-two college students from the Psychology Department's participant pool at Illinois State University participated in this experiment. The participants received partial course credit. On average, these participants were 20.40 years old $(S D=2.40$, Range $=$ $18-35)$. There were 25 freshmen, 15 sophomores, 29 juniors, 11 seniors, and two graduate students. The majority of the participants were women $(68 \%)$ with the minority men $(32 \%)$. The majority of the participants $(62 \%)$ were also Caucasian, but other ethnicities included African-American (18\%), Hispanic (14\%), Asian-American (4\%), and Mixed Ethnicity (2\%). Most students (75\%) were not self-proclaimed musicians but some $(20 \%)$ were. Trained or otherwise, most of these students had no training in playing or singing music $(38 \%)$, but students also had some training $(20 \%)$, a little $(24 \%)$, a fair amount (9\%), and a lot of training (10\%). However, music was highly important to these participants with 34\% indicating a lot, 54\% indicating a fair amount, $10 \%$ indicating some, and only $2 \%$ indicating not at all. Other demographic questions collected but not reported are shown in Appendix A.

Three participants' data were completely removed for all six songs because they did not meet the operational definitions of the experiment. Other participants' data were also removed because they did not meet the manipulation check. Data removed from the 
specific songs in which they did not meet the manipulation included two peoples' data from the unfamiliar song that induced happiness, five people's data from the unfamiliar song that induced sadness, and two peoples' data from the familiar song that induced happiness.

\title{
Materials
}

\begin{abstract}
Absorption
To measure absorption, this experiment used Sandstrom and Russo's (2013) Absorption in Music Scale (AIMS). The AIMS is a 34-item scale that measures how easily the participants can immerse themselves in the music while ignoring the outside world. It uses 1 (Strongly Disagree) to 5 (Strongly Agree) Likert type scales. Cronbach's alphas for this scale range from .91 to .94 in past experiments (Hogue, 2013; Sandstrom \& Russo, 2013). A test-retest correlation with an average time difference of 50.3 days was .91, and the AIMS correlated positively and strongly with the Tellegen Absorption Scale $(r=.76$; Sandstrom \& Russo, 2013). For this experiment, Cronbach's alpha was .89. See Appendix B for the scale.
\end{abstract}

\section{Liking}

This experiment used Schafer and Sedlmeier's (2010) Preference Subscale, which is a 6-item scale with response choices ranging from 1 (I do not agree at all) to 10 (I totally agree) in Likert-type scales. Cronbach's alphas for this scale have ranged from .88 to .90 (Hogue, 2013) and from .94 to .96 (Schafer \& Sedlmeier, 2010). For this experiment, Cronbach's alphas ranged from .82 to .94. See Appendix C for the scale. 


\section{Communion}

This experiment used Schafer and Sedlmeier's (2010) Communication subscale to measure Levinson's (1997) idea of communion with music. There are seven items in this scale, which use Likert-type scales of 1 (I do not agree at all) to 10 (I totally agree). Cronbach's alphas range from .94 to .95 in past experiments (Hogue, 2013; Schafer \& Sedlmeier, 2010). For this experiment, Cronbach's alphas ranged from .89 to .95. See Appendix $\mathrm{C}$ for the scale.

\section{Emotions and Other Measures}

How much happiness, sadness, satisfaction, and engagement each participant felt during the songs was measured using 1 (Not felt at all) to 5 (Intensely felt emotion) Likert-type scales. To help define satisfaction, participants were ask, "To you, is this satisfaction different from liking the song," which could be answered with either "Satisfaction is different from liking" or "Satisfaction is not different from liking." Also to help define satisfaction, participants were asked to to provide their own open-ended definition to "When you responded to the "satisfaction" item, what did 'satisfaction' mean to you?" Finally, familiarity with the song was be collected using Ilie and Thompson's (2011) Likert-type scale of 0 (I was not familiar with it prior to this experiment) to 5 (I was very familiar with it prior to this experiment). See Appendix D for al of the collected questions.

Definitions of satisfaction. A Friendman's test analyzes change from a categorical variable across multiple trials. It showed that the participants did not significantly change whether or not they thought that satisfaction was different than liking among the songs, $\chi^{2}(71)=10.11, p=.07$. Roughly equal amounts of people 
believed that satisfaction was different from liking as people who believed that satisfaction was not different from liking for just about every song.

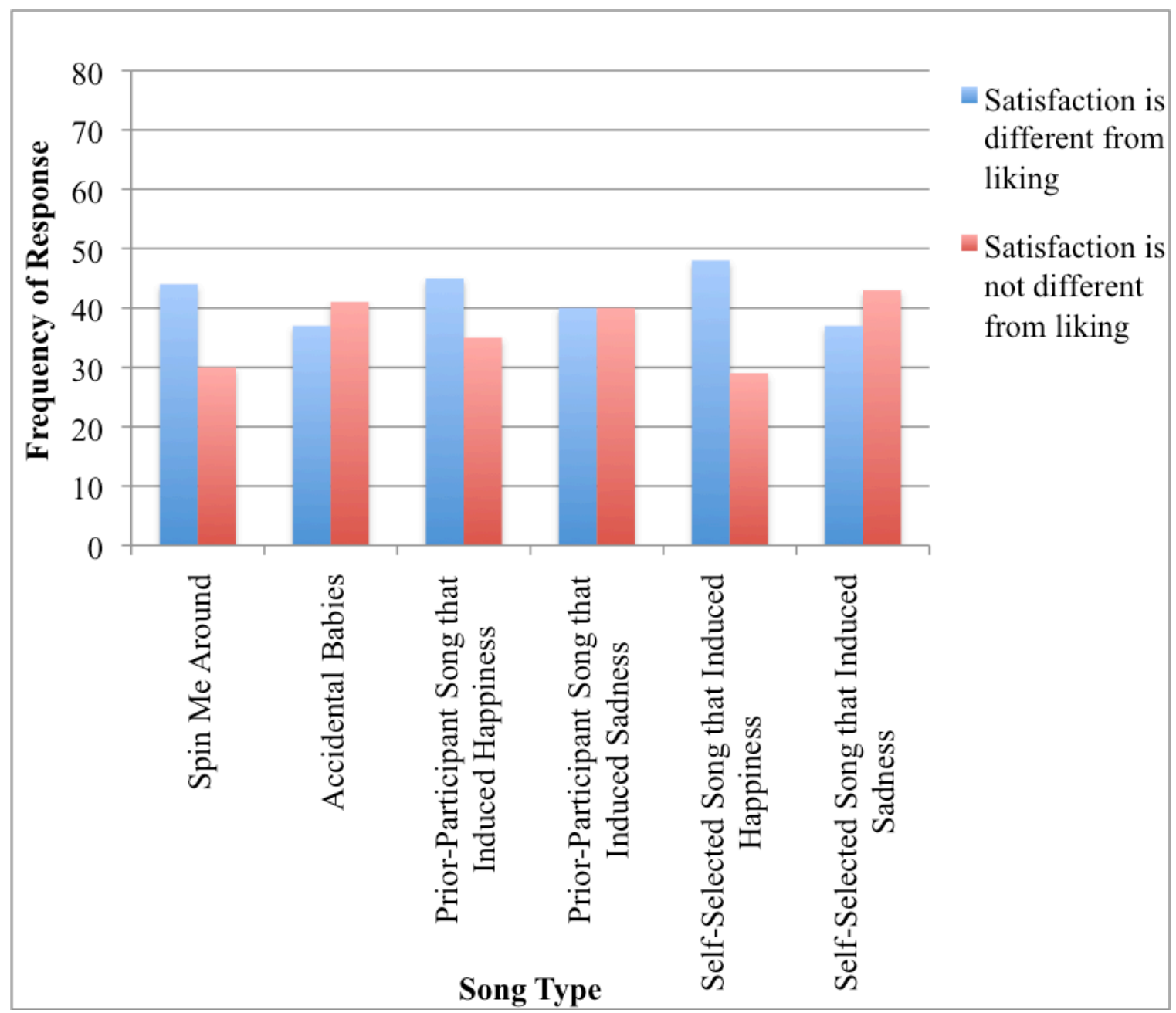

Figure 6. Satisfaction defined as liking among all six songs. The participants did not change their mind across the songs, and similar numbers of people thought that satisfaction was different than liking as who thought it was not different from liking.

The following are the frequencies of the responses to the open-ended question, "When you responded to the "satisfaction" item, what did 'satisfaction' mean to you?" These responses are how the participants defined satisfaction.

Unfamiliar song that induced happiness. Out of 80 participants, 15 people defined their amount of satisfaction with the unfamiliar song that induced happiness as 
enjoying the song. Ten participants stated satisfaction meant feeling happy after listening to the song. Another ten participants defined their satisfaction as liking the song. Six participants also stated that their amount of satisfaction meant feeling content.

Unfamiliar song that induced sadness. For this song, 12 participants defined their level of satisfaction as being fulfilled. There were six participants who were not fulfilled and six who were fulfilled. Nine participants defined their level of satisfaction as being content. Other definitions included enjoying the song (eight participants), enjoying the emotion that was evoked (seven participants), liking the song (four participants), and relating to the song (four participants).

Prior-participant song that induced happiness. Seventeen participants stated that their amount of satisfaction meant enjoying the song. Other definitions included feeling happy (14 participants) and being content (nine participants).

Prior-participant song that induced sadness. More participants (13 participants) defined satisfaction as being content than any other response. Other responses included enjoying the song (12 participants), liking the song (12 participants), and being happy from the song (eight participants).

Familiar song that induced happiness. Sixteen participants described their amount of satisfaction as enjoying the song. Other definitions included feeling happy (13 participants), liking the song (10 participants), and bringing back pleasant memories (10 participants).

Familiar song that induced sadness. Sixteen participants listed that their amount of satisfaction meant that they enjoyed the song. Other definitions included being content 
(eight participants), liking the song (six participants), relating to the song (six participants), and obtaining something positive from the song (six participants).

\section{Musical Stimuli}

See Table 1 for details about all the songs used in this experiment.

Unfamiliar songs. The unfamiliar song that induced happiness was Spin Me Around by Patent Pending. Its key was G major, and its tempo was 120 beats per minute.

The unfamiliar song that induced sadness was Accidental Babies by Damien Rice. Its key was A minor, and its tempo was about 60 beats per minute. The song utilized rubato throughout.

Familiar songs. The familiar and prior-participant songs (self-selected and priorparticipant songs, respectively) in this experiment were dependent upon what songs the participants indicated made them happy and sad. Before participating, the participants indicated what two songs made them happy and what two songs made them sad. For each participant, the experimenter chose one song that induced sadness and one that induced happiness based on what was available in iTunes, what the prior participant chose, and what song had the shortest amount of time. Two songs were chosen by different participants as songs that induced happiness and songs that induced sadness. These songs were Sugar by Maroon 5 and Stay with Me by Sam Smith. All other songs had the potential to be chosen by multiple participants but were not chosen and songs that induced happiness and sadness. Table 1 and Table 2 show the lists of songs that the participants said made them happy and sad, respectively. 
Table 1

List of Songs that Induced Happiness

\begin{tabular}{|c|c|c|c|}
\hline Title & Artist & Genre & Modality \\
\hline All for You (Full Band Version) & Sister Hazel & Rock & Ab Maj \\
\hline Always Alright & Alabama Shakes & Alternative & E Maj \\
\hline Amazed & Lonestar & Country & $\mathrm{Ab} \mathrm{Maj}$ \\
\hline American Kids & Kenny Chesney & Country & E Min \\
\hline Barbie Girl (Radio) & Aqua & Pop & E Maj \\
\hline Beachin' & Jake Owen & Country & F\# Maj \\
\hline Beautiful & Meshell Ndegeocello & R\&B/Soul & D Maj \\
\hline Besides & Sam Behymer & Singer/Songwriter & Ab Maj \\
\hline Blame (feat. John Newman) & Calvin Harris & Dance & $\mathrm{Eb} \mathrm{Maj}$ \\
\hline Blank Space & Taylor Swift & Pop & F Maj \\
\hline Break Free (feat. Zedd) & Ariana Grande & Pop & Eb Maj \\
\hline Colorado Sunrise & $3 \mathrm{OH} ! 3$ & Alternative & F\# Maj \\
\hline Come on Eileen & $\begin{array}{l}\text { Dexy's Midnight } \\
\text { Runners }\end{array}$ & Rock & D Major \\
\hline Countdown & Beyoncé & Pop & F Major \\
\hline Crazy Girl & Eli Young Band & Country & E Major \\
\hline $\begin{array}{l}\text { Crown (feat. Boaz van de Beatz, } \\
\text { Mike Posner \& RiFF RAFF) }\end{array}$ & Diplo & Dance & Bb Major \\
\hline Dancing Queen & $\mathrm{ABBA}$ & Pop & A Major \\
\hline Danza Kuduro (feat. Lucenzo) & $\begin{array}{l}\text { Don Omar \& } \\
\text { Lucenzo }\end{array}$ & Latin Urban & C Major \\
\hline Demons & Zeds Dead & Dance & F\# Minor \\
\hline Dinosaur Laser Fight & Ninja Sex Party & Comedy & A Major \\
\hline Doin' Time (Uptown Dub) & Sublime & Alternative & F Minor \\
\hline Electric Feel & MGMT & Alternative & C Minor \\
\hline Energy & Drake & Hip-Hop/Rap & Eb Minor \\
\hline Freak Hoe & Speaker Knockerz & Hip-Hop/Rap & B Minor \\
\hline Free Fallin' & Tom Petty & Rock & F Major \\
\hline Girlfriend & Avril Lavigne & Pop & D Major \\
\hline Go the Distance & Roger Bart & Soundtrack & A Major \\
\hline $\begin{array}{l}\text { Happy (From "Despicable Me } \\
\text { 2") }\end{array}$ & Pharrell Williams & Pop & F Minor \\
\hline Heartbeat Song & Kelly Clarkson & Pop & F\# Major \\
\hline Hell On the Heart & Eric Church & Country & C Major \\
\hline Here Comes the Sun & The Beatles & Rock & A Major \\
\hline Homegrown & Zac Brown Band & Country & Gb Major \\
\hline Honey, I'm Good. & Andy Grammer & Pop & A Major \\
\hline I Don't Dance & Lee Brice & Country & $\begin{array}{l}\text { Db Major } \\
\text { Continues) }\end{array}$ \\
\hline
\end{tabular}




\begin{tabular}{|c|c|c|c|}
\hline Title & Artist & Genre & Modality \\
\hline $\begin{array}{l}\text { I Don't Get Tired (\#IDGT) [feat. } \\
\text { August Alsina] }\end{array}$ & Kevin Gates & Hip-Hop/Rap & Db Major \\
\hline It's Oh So Quiet & Björk & Pop & Eb Major \\
\hline Just Gettin' Started & Jason Aldean & Country & G\# Minor \\
\hline Just the Way You Are & Bruno Mars & Pop & F Major \\
\hline Laid & Matt Nathanson & Soundtrack & C Major \\
\hline $\begin{array}{l}\text { Lean On (feat. MØ \& DJ } \\
\text { Snake) }\end{array}$ & Major Lazer & Electronic & G Minor \\
\hline Leave the Night On & Sam Hunt & Country & A Major \\
\hline Masterpiece & Jessie J & Pop & C Minor \\
\hline Maybe Not & Cat Power & Rock & A Minor \\
\hline Meddler & August Burns Red & Metal & C Minor \\
\hline Mr. Jones & Counting Crows & Rock & C Major \\
\hline My Eyes (feat. Gwen Sebastian) & Blake Shelton & Country & E Major \\
\hline Nobody Love & Tori Kelly & Pop & Eb Major \\
\hline Ready Set Roll & Chase Rice & Country & C Major \\
\hline Title & Artist & Genre & Modality \\
\hline Right Above It (feat. Drake) & Lil Wayne \& Drake & Hip-Hop/Rap & Eb Minor \\
\hline Shake It Off & Taylor Swift & Pop & G Major \\
\hline Simple As This & Jake Bugg & Alternative & Ab Major \\
\hline Spin Me Around & Patent Pending & Rock & G Major \\
\hline Step By Step & $\begin{array}{l}\text { New Kids On the } \\
\text { Block }\end{array}$ & Pop & E Minor \\
\hline Stutter & Marianas Trench & Alternative & E Major \\
\hline Style & Taylor Swift & Pop & D Major \\
\hline Summer & Calvin Harris & Dance & G Major \\
\hline Sun Daze & Florida Georgia Line & Country & E Major \\
\hline Take On Me & a-ha & Pop & A Major \\
\hline Take Your Mama & Scissor Sisters & Pop & $\mathrm{Bb}$ Major \\
\hline Talk Dirty (feat. 2 Chainz) & Jason Derulo & Pop & F\# Minor \\
\hline That's It & Post Malone & Hip Hop/Rap & G Minor \\
\hline The Man & Aloe Blacc & Pop & D Major \\
\hline This Time (feat. J Cole) & Melanie Fiona & R\&B/Soul & E Major \\
\hline Thnks Fr Th Mmrs & Fall Out Boy & Rock & $\begin{array}{l}\text { Bb } \\
\text { Minor/ } \\
\text { D Major }\end{array}$ \\
\hline Time of Your Life & Kid Ink & Hip-Hop/Rap & C Minor \\
\hline Trumpets & Jason Derulo & Pop & C Major \\
\hline Ugly Heart & G.R.L. & Pop & A Major \\
\hline $\begin{array}{l}\text { Uptown Funk (feat. Bruno } \\
\text { Mars) }\end{array}$ & Mark Ronson & Pop & D Minor \\
\hline Vivir Mi Vida & Marc Anthony & Salsa y Tropical & C Minor \\
\hline Wasted (feat. Matthew Koma) & Tiësto & Dance & $\begin{array}{l}\text { D Major } \\
\text { Continues) }\end{array}$ \\
\hline
\end{tabular}




\begin{tabular}{lllc}
\hline Title & Artist & Genre & Modality \\
\hline Work It & Missy Elliott & Hip-Hop/Rap & C Minor \\
Worth It (feat. Kid Ink) & Fifth Harmony & Pop & C Minor \\
You Shook Me All Night Long & AC/DC & Rock & G Major \\
\hline
\end{tabular}

Table 2

List of Songs that Induced Sadness

\begin{tabular}{|c|c|c|c|}
\hline Title & Artist & Genre & Modality \\
\hline Accidental Babies & Damien Rice & Alternative & A Minor \\
\hline Adam's Song & Blink-182 & Alternative & C Major \\
\hline All Along & Kid Cudi & Hip-Hop/Rap & C Major \\
\hline Banged and Blown Through & Saul Williams & Hip-Hop/Rap & D Minor \\
\hline Be Still & The Fray & Pop & G Major \\
\hline $\begin{array}{l}\text { Beneath Your Beautiful (feat. } \\
\text { Emeli Sandé) }\end{array}$ & Labrinth & Pop & Eb Major \\
\hline Black Sun & Death Cab for Cutie & Alternative & B Minor \\
\hline Blue (feat. Blue Ivy) & Beyoncé & Pop & F\# Major \\
\hline Breakdown & Seether & Pop & Eb Minor \\
\hline Can You Hear Me & Missy Elliott & Hip-Hop/Rap & Ab Major \\
\hline Cinderella & $\begin{array}{l}\text { Steven Curtis } \\
\text { Chapman }\end{array}$ & $\begin{array}{l}\text { Christian \& } \\
\text { Gospel }\end{array}$ & $\mathrm{Bb}$ Major \\
\hline Colorblind & Counting Crows & Rock & F Major \\
\hline $\begin{array}{l}\text { Comptine d'un autre été, l'après- } \\
\text { midi }\end{array}$ & Yann Tiersen & Soundtrack & E Minor \\
\hline Creep & Radiohead & Rock & G Major \\
\hline Dance With My Father & Luther Vandross & R\&B/Soul & $\mathrm{Bb}$ Major \\
\hline Did You Wrong & Pleasure P & R\&B/Soul & C Major \\
\hline Dust In the Wind & Kansas & Rock & A Minor \\
\hline Every Breath You Take & The Police & Rock & Ab Major \\
\hline Face Down & $\begin{array}{l}\text { The Red Jumpsuit } \\
\text { Apparatus }\end{array}$ & Rock & $\mathrm{Bb}$ Major \\
\hline Fall for You & $\begin{array}{l}\text { Secondhand } \\
\text { Serenade }\end{array}$ & Alternative & C Major \\
\hline $\begin{array}{l}\text { Good Riddance (Time of Your } \\
\text { Life) }\end{array}$ & Green Day & Pop & G Major \\
\hline Gravity & Sara Bareilles & Pop & C Major \\
\hline Happy Ending & Mike Stud & Hip-Hop/Rap & Db Major \\
\hline Hey Pretty Girl & Kip Moore & Country & D Major \\
\hline
\end{tabular}

(Table Continues) 


\begin{tabular}{|c|c|c|c|}
\hline Title & Artist & Genre & Modality \\
\hline How to Save a Life & The Fray & Rock & Bb Major \\
\hline Hurt & Johnny Cash & Country & A Minor \\
\hline I Drive Your Truck & Lee Brice & Country & B Major \\
\hline I Loved Her First & Heartland & Country & E Major \\
\hline I Swear & $\begin{array}{l}\text { John Michael } \\
\text { Montgomery }\end{array}$ & Country & Db Major \\
\hline I Was Here & Beyoncé & Pop & G Major \\
\hline I Will Follow You Into the Dark & Death Cab for Cutie & Rock & F Major \\
\hline I'd Rather Go Blind & Beyoncé & Soundtrack & A Major \\
\hline I'm Not the Only One & Sam Smith & Pop & F Major \\
\hline If I Die Young & The Band Perry & Country & E Major \\
\hline If It Means a Lot to You & $\begin{array}{l}\text { A Day to } \\
\text { Remember }\end{array}$ & Rock & G Minor \\
\hline Jar of Hearts & Christina Perri & Pop & C Minor \\
\hline Jesus, Take the Wheel & Carrie Underwood & Pop & A Major \\
\hline Let Go & Frou Frou & Alternative & D Minor \\
\hline Let It Be & The Beatles & Rock & C Major \\
\hline Marry Me & Jason Derulo & Pop & G Major \\
\hline Mary, Did You Know? & Cee Lo Green & Holiday & Eb Minor \\
\hline Mi Víejo & Vicente Fernández & $\begin{array}{l}\text { Regional } \\
\text { Mexicano }\end{array}$ & G Minor \\
\hline Mr. Rager & Kid Cudi & Hip-Hop/Rap & B Minor \\
\hline My Heart Will Go On & Céline Dion & Pop & E Major \\
\hline My Mine & Jhene Aiko & R\&B/Soul & A Minor \\
\hline Nothing But A Miracle & Diane Birch & Pop & $\mathrm{Bb}$ Minor \\
\hline Samson & Regina Spektor & Alternative & D Major \\
\hline Say Goodbye & Chris Brown & Pop & B Major \\
\hline See You Again (feat. Charlie Puth) & Wiz Khalifa & Hip-Hop/Rap & $\mathrm{Bb}$ Minor \\
\hline Skinny Love & Bon Iver & Alternative & $\mathrm{Bb}$ Major \\
\hline Skyscraper & Demi Lovato & Pop & C Major \\
\hline Slow Dancing In a Burning Room & John Mayer & Rock & G Major \\
\hline Sorrow & Flyleaf & Rock & E Major \\
\hline Stay (feat. Mikky Ekko) & Rihanna & Pop & D Minor \\
\hline Still Around & $3 \mathrm{OH} ! 3$ & Alternative & A Minor \\
\hline Take Me to Church & Hozier & Alternative & $\mathrm{Bb}$ Major \\
\hline Tears In Heaven & Eric Clapton & Rock & E Minor \\
\hline The Chain & Ingrid Michaelson & Pop & A Major \\
\hline The House That Built Me & Miranda Lambert & Country & F Major \\
\hline Therapy & All Time Low & Alternative & F Major \\
\hline This Woman's Work (Uncut) & Maxwell & R\&B/Soul & A Major \\
\hline
\end{tabular}




\begin{tabular}{|c|c|c|c|}
\hline Title & Artist & Genre & Modality \\
\hline Wars & Hurt & Rock & Ab Major \\
\hline Watching You & Rodney Atkins & Country & G Minor \\
\hline $\begin{array}{l}\text { We Found Love (feat. Calvin } \\
\text { Harris) }\end{array}$ & Rihanna & Pop & D Major \\
\hline What Hurts the Most & Rascal Flatts & Country & F\# Major \\
\hline When I'm Gone & Eminem & Hip-Hop/Rap & F Minor \\
\hline When She Loved Me & Sarah McLachlan & Alternative & $\mathrm{Bb}$ Minor \\
\hline When You're Gone & Avril Lavigne & Pop & F Major \\
\hline $\begin{array}{l}\text { Where'd You Go (feat. Holly } \\
\text { Brook \& Jonah Matranga) }\end{array}$ & Fort Minor & Hip-Hop/Rap & G Major \\
\hline $\begin{array}{l}\text { Whiskey Lullaby (feat. Alison } \\
\text { Krauss) }\end{array}$ & $\begin{array}{l}\text { Brad Paisley \& } \\
\text { Alison Krauss }\end{array}$ & Country & E Major \\
\hline Who Knew & $\mathrm{P} ! \mathrm{NK}$ & Pop & B Minor \\
\hline You Are the Moon & The Hush Sound & Alternative & A Minor \\
\hline Young and Beautiful & Lana Del Rey & Soundtrack & F\# Minor \\
\hline Youth & Daughter & Alternative & B Minor \\
\hline
\end{tabular}

Once data collection ended, an independent third-party who was blind to the purpose of the study analyzed the songs to record their tempo, mode, and lyrical content. See Appendix E for the questions the rater answered. A Cohen Kappa analysis showed that the rater agreed with the participants $17 \%$ of the time, which was a significant amount, $p=.03$, but only represents slight agreement (Viera \& Garrett, 2005). More songs had a major modality (68\%) than a minor modality $(32 \%)$, but the participants' ratings of the emotionality of the songs and the modality of the songs were not significantly related based on a chi-square test of association, $\chi^{2}(2)=1.75, p=.42$. For the familiar songs that induced happiness, $29 \%$ of the songs had a minor modality and $71 \%$ had a major modality. For the familiar songs that induced sadness, $36 \%$ of these songs had a minor modality and $64 \%$ had a major modality.

Tempo was not different between the songs with a major modality $(M=95.51, S E$ $=2.72)$ and the songs with a minor modality $(M=99.95, S E=3.98), F(1,144)=.85, p=$ 
.36. The familiar songs that induced happiness $(M=105.43, S E=3.49)$ had a faster tempo than the familiar songs that induced sadness $(M=90.03, S E=3.33), F(1,144)=$ $10.19, p=.002$. The interaction between the modality of the songs and the emotion that the songs induced in the participants did not significantly impact tempo, $F(1,144)=1.30$, $p=.26$.

\section{Instruments}

The participants listened to the music using Bose noise-cancelling headphones. A computer disseminated the music to the headphones and allowed the participants to answer the dependent measures.

\section{Design}

This experiment manipulated familiarity and compared six songs: two familiar songs (self-selected), two unfamiliar (experimenter-given) songs that were given to every participant, and two songs from the prior participant that on average were somewhat familiar. One song from each category was intended to induce sadness; the other song was intended to induce happiness. As each participant heard all six songs, this experiment utilized a within-subjects design, counterbalanced using a balanced Latin-square, Williams design. See Table 3 for the counterbalancing design. For each counterbalancing set, the AIMS was a between-subjects variable, where the AIMS either preceded the counterbalancing set or succeeded the counterbalancing set, creating two conditions for each of the six counterbalancing sets. 
Table 3

Counterbalancing Sets

\begin{tabular}{ccccccc}
\hline Sets & $\begin{array}{c}\text { First } \\
\text { Song }\end{array}$ & $\begin{array}{c}\text { Second } \\
\text { Song }\end{array}$ & $\begin{array}{c}\text { Third } \\
\text { Song }\end{array}$ & $\begin{array}{c}\text { Fourth } \\
\text { Song }\end{array}$ & $\begin{array}{c}\text { Fifth } \\
\text { Song }\end{array}$ & $\begin{array}{c}\text { Sixth } \\
\text { Song }\end{array}$ \\
\hline A & 1 & 2 & 6 & 3 & 5 & 4 \\
B & 2 & 3 & 1 & 4 & 6 & 5 \\
C & 3 & 4 & 2 & 5 & 1 & 6 \\
D & 4 & 5 & 3 & 6 & 2 & 1 \\
E & 5 & 6 & 4 & 1 & 3 & 2 \\
F & 6 & 1 & 5 & 2 & 4 & 3 \\
\hline Note: & 1 & $=$ & Self-selected Song that Induced Sadness \\
& $2=$ & Self-selected Song that Induced Happiness \\
& 3 & Prior-participant Song that Induced Sadness \\
& 5 Prior-participant Song that Induced Happiness \\
& 6 Experimenter-given Song that Induced Sadness (Accidental Babies)
\end{tabular}

To randomly assign each participant to a set and condition, the experimenter used a random number generator to create a randomly organized list of numbers between one and 12. Numbers 1 and 2, for example, corresponded to Set 1- Pre AIMS and Set 1- Post AIMS, respectively, but these two conditions were not in successive order. Participants were assigned to the randomly generated sets and conditions based in the order in which they agreed to participate.

\section{Procedure}

Every participant entered the lab and signed the informed consent form. Once they agreed to participate, they completed the demographic questions. Half of the participants filled out the AIMS after the demographic questions. Everyone then listened to the six songs and filled out the dependent measures after each song. After listening to 
the entirety of all six songs and filling out the dependent measures after each song, the half of the participants who did not fill out the AIMS before the songs filled out the AIMS. At this point, participants were assessed for emotional distress, debriefed, and given their partial course credit. 


\section{CHAPTER IV \\ RESULTS \\ Preliminary Results}

\section{Correlations}

Communion and liking, satisfaction and liking, and happiness and satisfaction were significantly, positively correlated amongst all six conditions. Sadness and liking were only significantly, positively correlated in the songs that induced sadness.

Table 4

Correlations Among the Unfamiliar Songs that Induced Happiness

\begin{tabular}{|c|c|c|c|c|c|c|}
\hline & Absorption & Happiness & Sadness & Satisfaction & Liking & Communion \\
\hline Absorption & 1 & 0 & $.30 * *$ & -.06 & .21 & .13 \\
\hline Happiness & & 1 & $-.24 *$ & $.77 * *$ & $.59 * *$ & $.68 * *$ \\
\hline Sadness & & & 1 & -.14 & -.13 & -.07 \\
\hline Satisfaction & & & & 1 & $.55 * *$ & $.68 * *$ \\
\hline Liking & & & & & 1 & $.74 * *$ \\
\hline
\end{tabular}

Note: $* p<.05$

$* * p<.01$

Table 5

Correlations Among the Unfamiliar Songs that Induced Sadness

\begin{tabular}{rrrrrrr}
\hline & Absorption & Happiness & Sadness & Satisfaction & Liking & Communion \\
\hline Absorption & 1 & .11 & .09 & .10 & $\mathbf{. 2 5 *}$ & $\mathbf{. 2 5}^{*}$ \\
Happiness & & 1 & -.12 & $\mathbf{. 5 6 * *}$ & $\mathbf{. 5 0 * *}$ & $.40^{* *}$ \\
Sadness & & 1 &. $\mathbf{2 5}^{*}$ & $\mathbf{. 2 3 *}$ & $\mathbf{. 3 0 * *}$ \\
Satisfaction & & & 1 & $\mathbf{. 5 1 * *}$ & $\mathbf{. 4 6}^{* *}$ \\
Liking & & & & 1 & $\mathbf{. 7 3 * *}$ \\
\hline
\end{tabular}

Note: $* p<.05$

$$
* * p<.01
$$


Table 6

Correlations Among the Prior-participant Songs that Induced Happiness

\begin{tabular}{rrrrrrr}
\hline & Absorption & Happiness & Sadness & Satisfaction & Liking & Communion \\
\hline Absorption & 1 & 0 & .11 & -.04 & .10 & .09 \\
Happiness & & 1 & -.07 & $.71^{* *}$ & $.61^{* *}$ & $.64^{* *}$ \\
Sadness & & & 1 & .11 & -.14 & .03 \\
Satisfaction & & & & 1 & $.65^{* *}$ & $.64^{* *}$ \\
Liking & & & & & 1 & $.73^{* *}$ \\
\hline
\end{tabular}

Note: $* p<.05$

$* * p<.01$

Table 7

Correlations Among the Prior-participant Songs that Induced Sadness

\begin{tabular}{rrrrrrr}
\hline & Absorption & Happiness & Sadness & Satisfaction & Liking & Communion \\
\hline Absorption & 1 & .02 & .13 & .07 & .14 & .20 \\
Happiness & & 1 & -.20 & $.59^{* *}$ & $.53^{* *}$ &. $\mathbf{4 6 * *}$ \\
Sadness & & & 1 & .08 & .17 &. $\mathbf{3 4 * *}$ \\
Satisfaction & & & & 1 &. $\mathbf{6 8 * *}$ &. $\mathbf{7 1 * *}$ \\
Liking & & & & & 1 &. $\mathbf{7 8 *}$ \\
\hline
\end{tabular}

Note: $* p<.05$

$* * p<.01$

Table 8

Correlations Among the Familiar Songs that Induced Happiness

\begin{tabular}{|c|c|c|c|c|c|c|}
\hline & Absorption & Happiness & Sadness & Satisfaction & Liking & Communion \\
\hline Absorption & 1 & .16 & .03 & 0 & $.31 * *$ & $.26 *$ \\
\hline Happiness & & 1 & -.16 & $-.40 * *$ & $.42 * *$ & $.24 *$ \\
\hline Sadness & & & 1 & -.11 & .10 & .06 \\
\hline Satisfaction & & & & 1 & $.48 * *$ & $.40 * *$ \\
\hline Liking & & & & & 1 & $.60 * *$ \\
\hline
\end{tabular}

Note: $* p<.05$

$* * p<.01$ 
Table 9

Correlations Among the Familiar Songs that Induced Sadness

\begin{tabular}{lllllll}
\hline & Absorption & Happiness & Sadness & Satisfaction & Liking & Communion \\
\hline Absorption & 1 & -.15 & $\mathbf{. 3 3} * *$ & .04 & $\mathbf{. 3 2} * *$ & $\mathbf{. 3 8 * *}$ \\
Happiness & 1 & $\mathbf{- 0 . 7}$ & $\mathbf{. 3 3} * *$ & -.05 & -.21 \\
Sadness & & & 1 & -.08 & $\mathbf{. 3 0} * *$ & $.47 * *$ \\
Satisfaction & & & & 1 & $\mathbf{. 3 9} * *$ & .19 \\
Liking & & & & & 1 & $\mathbf{. 7 3 * *}$ \\
\hline
\end{tabular}

Note: $* p<.05$

$* * p<.01$

\section{Familiarity Manipulation Check}

A repeated-measures ANOVA determined that familiarity differences among the songs existed, Greenhouse-Geisser $\varepsilon=.53, F(2.63,204.97)=171.00, p<.001, \eta_{\mathrm{p}}{ }^{2}=.69$. Bonferroni post-hoc analyses indicated that familiarity was higher for the two selfselected songs than the other four songs $(p s<.001)$ but not between the two self-selected songs, $p=1.00$. Familiarity was significantly lower in the two unfamiliar songs, experimenter-given songs (Accidental Babies and Spin Me Around) than the other four songs $(p s<.001)$ but were not different between each other, $p=1.00$. The two priorparticipant songs had higher familiarity scores than the two unfamiliar, experimentergiven songs $(p s<.001)$ and lower familiarity than the two self-selected songs $(p s<001)$ but did not differ between themselves, $p=1.00$. See Figure 5 for means and standard errors. In other words, the manipulation check worked. However, five people knew Spin Me Around, two people knew Accidental Babies, and two people did not know their selfselected song that induced happiness. Because of these manipulation errors, the scores from these songs were removed to reduce possible biases in further analyses. 


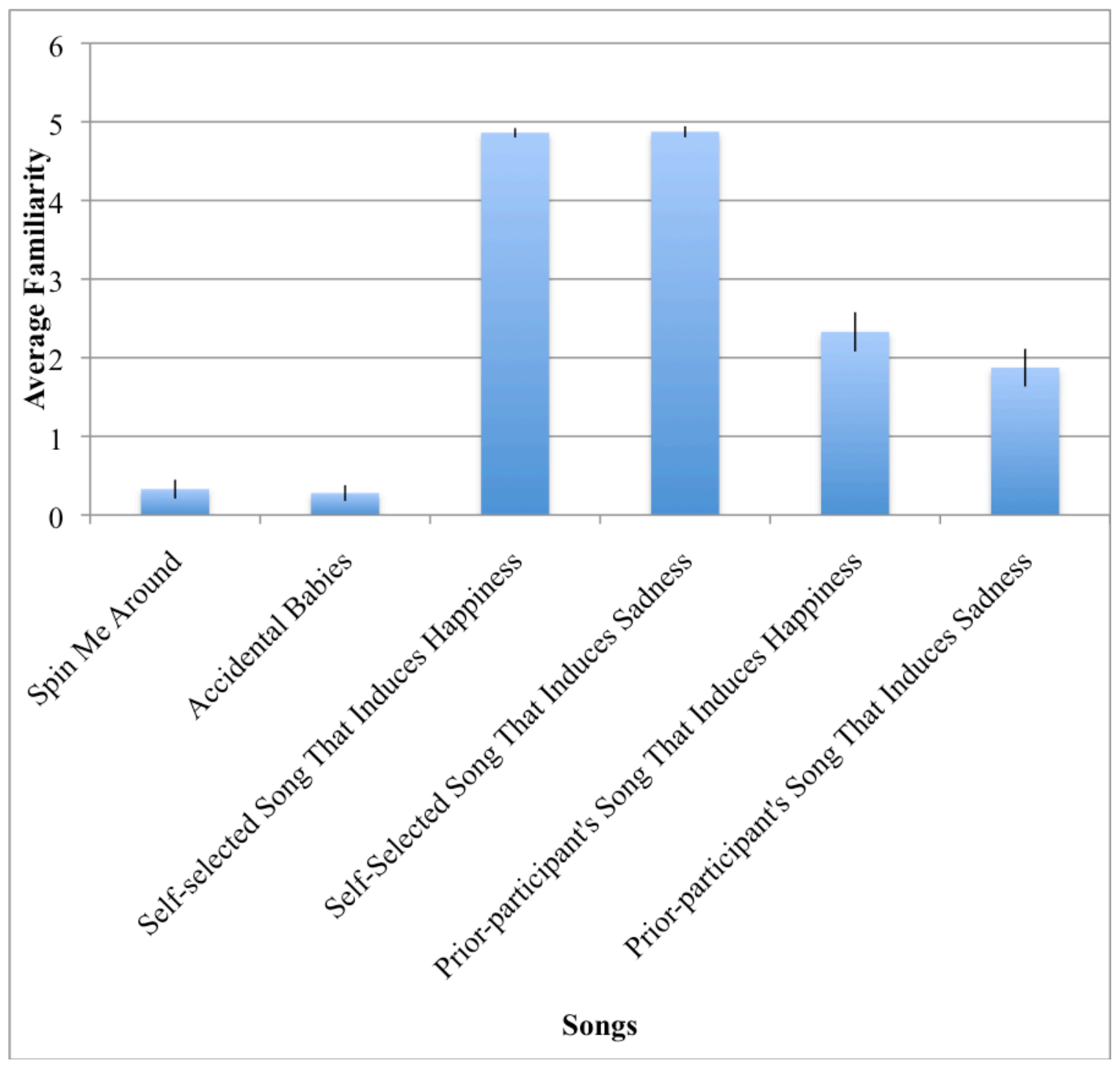

Figure 7. Familiarity manipulation check. This figure shows that the two experimentergiven songs were unfamiliar, the two self-selected songs were familiar, and the two priorparticipant's songs were somewhat familiar.

\section{Emotion}

A 2 (Within: Emotion: Happiness and Sadness) x 6 (Between: Random Assignment) x 2 (Between: Pre vs Post study AIMS test) x 6 (Within: Songs) mixed design ANOVA determined significant order effects on evoking emotion. The placement of the AIMS test did not affect how much emotion was evoked, $F(1,58)=.00, p=.99$, $\eta_{\mathrm{p}}{ }^{2}=.00$. The different random assignment sets by themselves also did not affect total 
evoked emotion, $F(5,58)=.66, p=.66, \eta_{\mathrm{p}}{ }^{2}=.05$. Total emotion was higher for happiness scores $(M=2.73, S E=.06)$ than sadness scores $(M=2.14, S E=.06)$, Wilk's $\Lambda$ $=.53, F(1,58)=51.79, p<.001, \eta_{\mathrm{p}}^{2}=.47$. The songs themselves also affected total evoked emotion, Wilk's $\Lambda=.33, F(5,54)=21.70, p<.001, \eta_{\mathrm{p}}{ }^{2}=.67$. The self-selected songs evoked more total emotion than the other four songs ( $p s \leq .001)$ but were not different between themselves, $p=1.00$. All other songs evoked similar amounts of total emotion compared to the other songs, $p=1.00$. See Figure 7 for the means and standard errors.

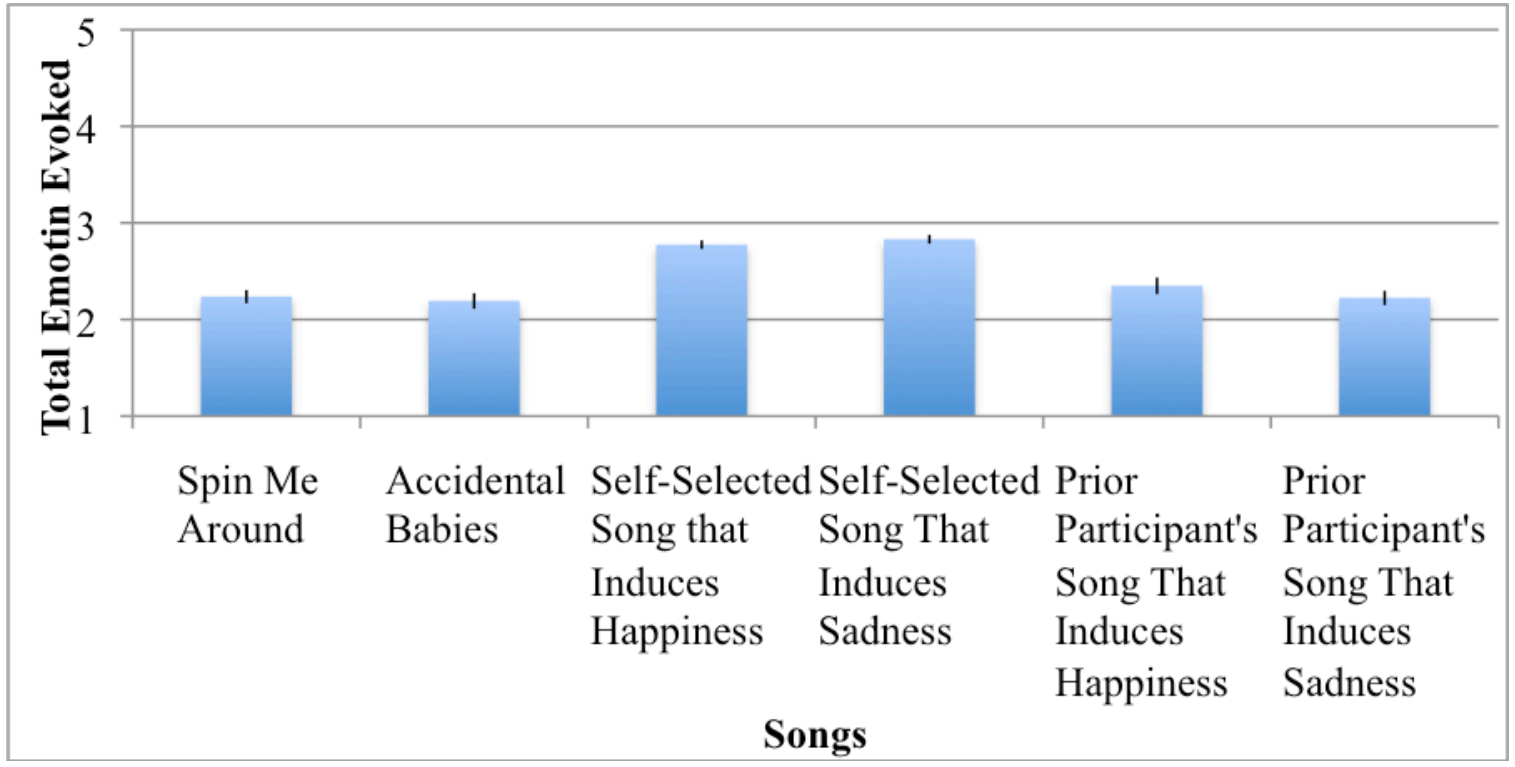

Figure 8. Emotion evoked for each song type. Self-selected songs evoked stronger emotions overall than the other types of songs.

The interactions between emotion and the AIMS test placement (Wilk's $\Lambda=.98$, $\left.F[1,58]=.89, p=.35, \eta_{\mathrm{p}}{ }^{2}=.02\right)$, between emotion and the random assignment sets (Wilk's $\Lambda=.88, F[5,58]=1.52, p=.20, \eta_{\mathrm{p}}{ }^{2}=.12$ ), between the song and the AIMS test placement (Wilk's $\left.\Lambda=.97, F[5,54]=.38, p=.86, \eta_{\mathrm{p}}{ }^{2}=.03\right)$, and between the songs and the random assignment sets (Wilk's $\Lambda=.64, F[25,202.10]=1.03, p=.42, \eta_{\mathrm{p}}{ }^{2}=.09$ ) did 
not significantly affect evoking the intended emotions. The interaction between the AIMS test placement and the random assignment sets significantly affected total evoked emotion, $F(5,58)=3.00, p=.02, \eta_{\mathrm{p}}{ }^{2}=.21$. Total evoked emotion significantly decreased for Set $\mathrm{B}(p=.002)$ but not for the other sets, $p \geq .10$. See the Figure 8 for the means and standard errors of this significant interaction.

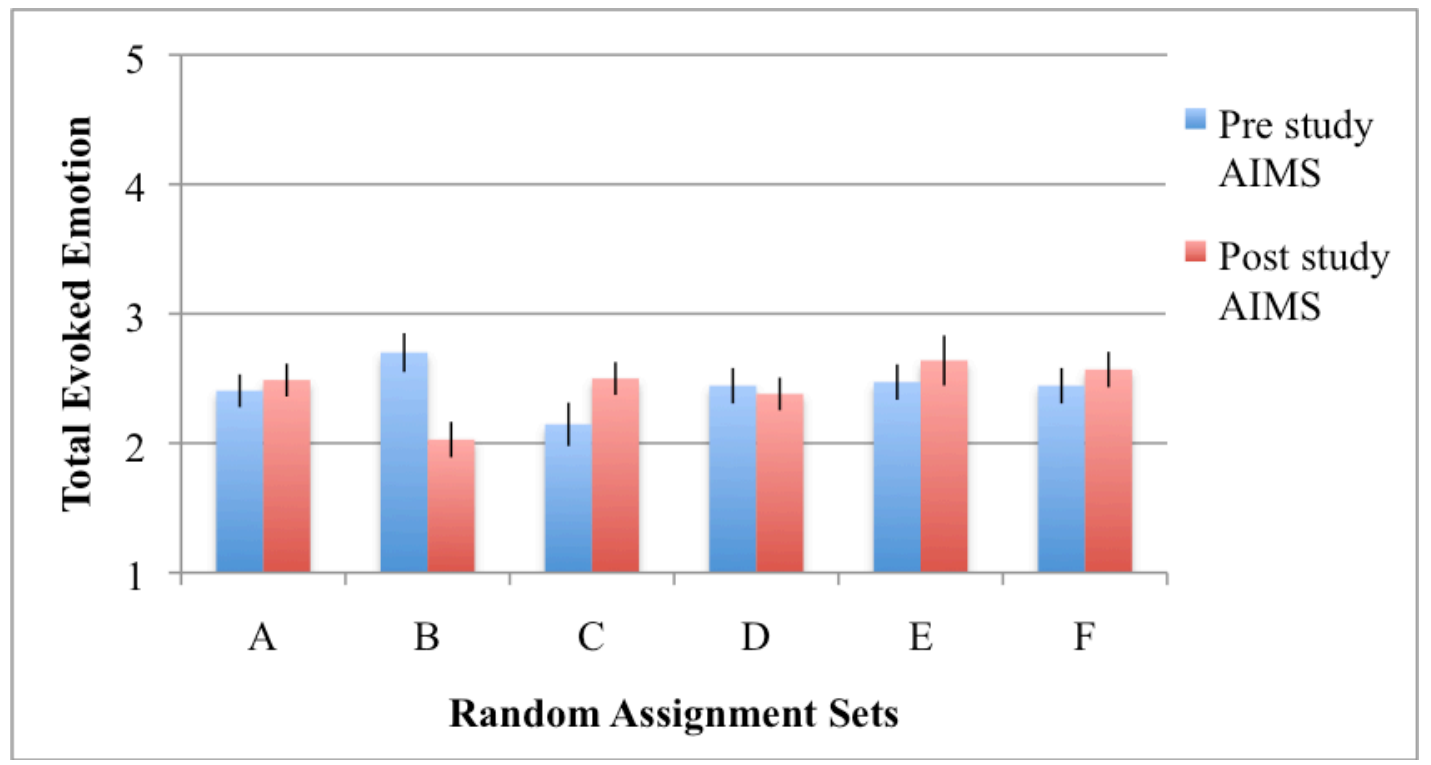

Figure 9. Absorption placement by random assignment on overall evoked emotion. Overall emotion was lower in the post-AIMS for Set B than it was for the pre-AIMS.

The interaction between the songs and the type of emotion evoked was also significant, Greenhouse-Geisser $\varepsilon=.71, F(3.55,202.15)=149.09, p<.001, \eta_{\mathrm{p}}{ }^{2}=.72$. Sping Me Around, the self-selected songs that induced happiness, and the prior participants' songs that induced happiness all evoked more happiness than sadness, $p s<$ .001. Accidental Babies and the self-selected song that induced sadness both evoked more sadness than happiness, $p<.001$. The prior participant's song that induced sadness did not induce more happiness or sadness, $p=.07$. See the Figure 9 for means and standard errors. 


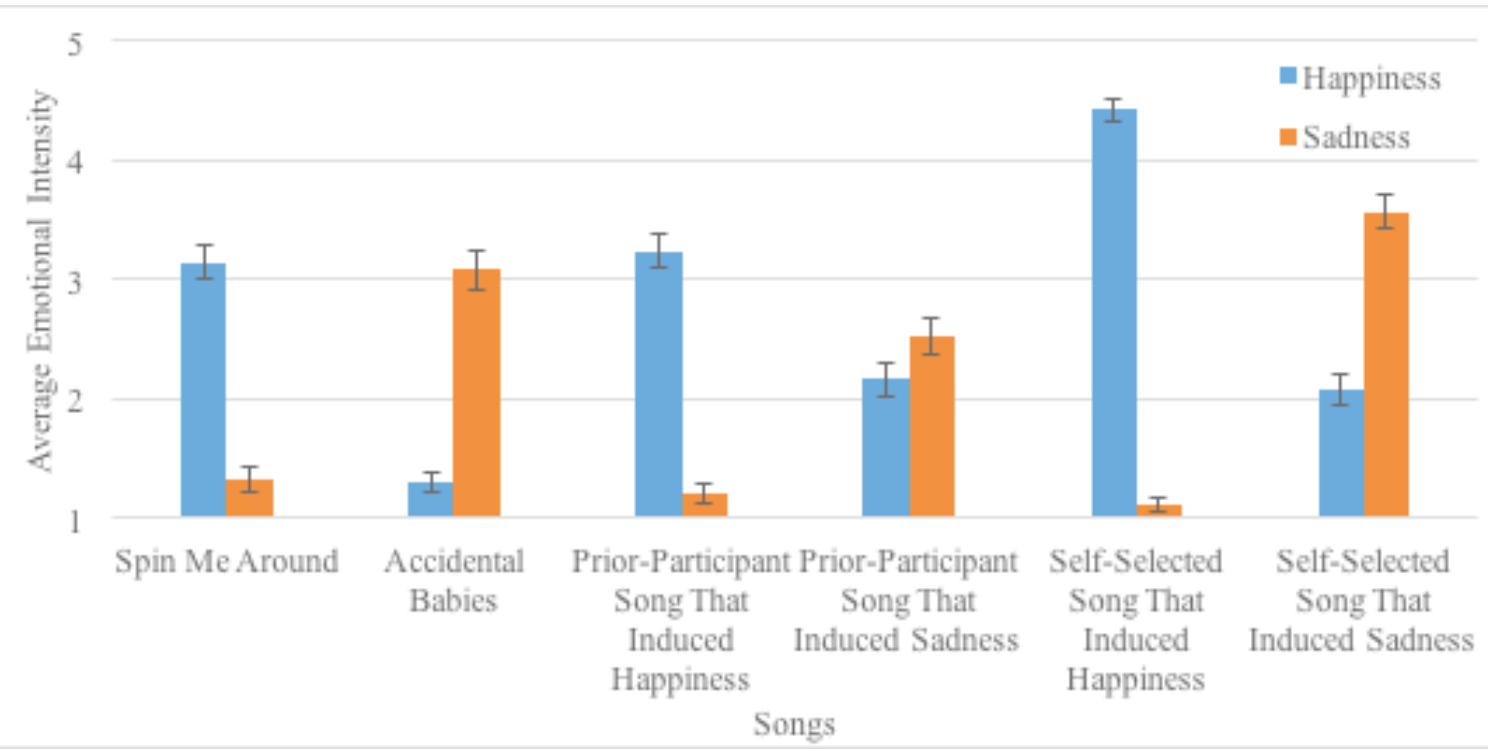

Figure 10. Song type on happiness and sadness. The songs that were supposed to induce happiness induced happiness, and the songs that were supposed to induce sadness induced sadness. The prior-participant's song that was supposed to induce sadness induced equal amounts of happiness and sadness.

The three-way interaction among the emotions, AIMS test placement, and the random assignment sets (Wilk's $\Lambda=.93, F[5,58]=1.52, p=.49, \eta_{\mathrm{p}}{ }^{2}=.07$ ) and among the emotion, songs, and random assignment sets (Wilk's $\Lambda=.98, F[5,54]=.24, p=.94$, $\left.\eta_{\mathrm{p}}^{2}=.02\right)$ did not significantly affect the amount of evoked total emotion. The three-way interaction among the emotion evoked, the songs, and the random assignment sets, however, did affect the strength of the emotions, Wilk's $\Lambda=.52, F(25,202.10)=1.57, p$ $=.048, \eta_{\mathrm{p}}{ }^{2}=.12$. Figure 10 visually depicts the three-way interaction with the means for happiness. For happiness, Spin Me Around had lower happiness scores in set C than it did in all other sets $(p s \leq .03)$ but Set A. In Set C, Spin Me Around was the last song, and in Set A, it was after their self-selected song that induced happiness. The happiness scores from Accidental Babies were higher in Set E than they were in all other sets $(p s \leq .047)$ 
except Set A. In Set E, Accidental Babies was the first song, and it was the penultimate song in Set A.

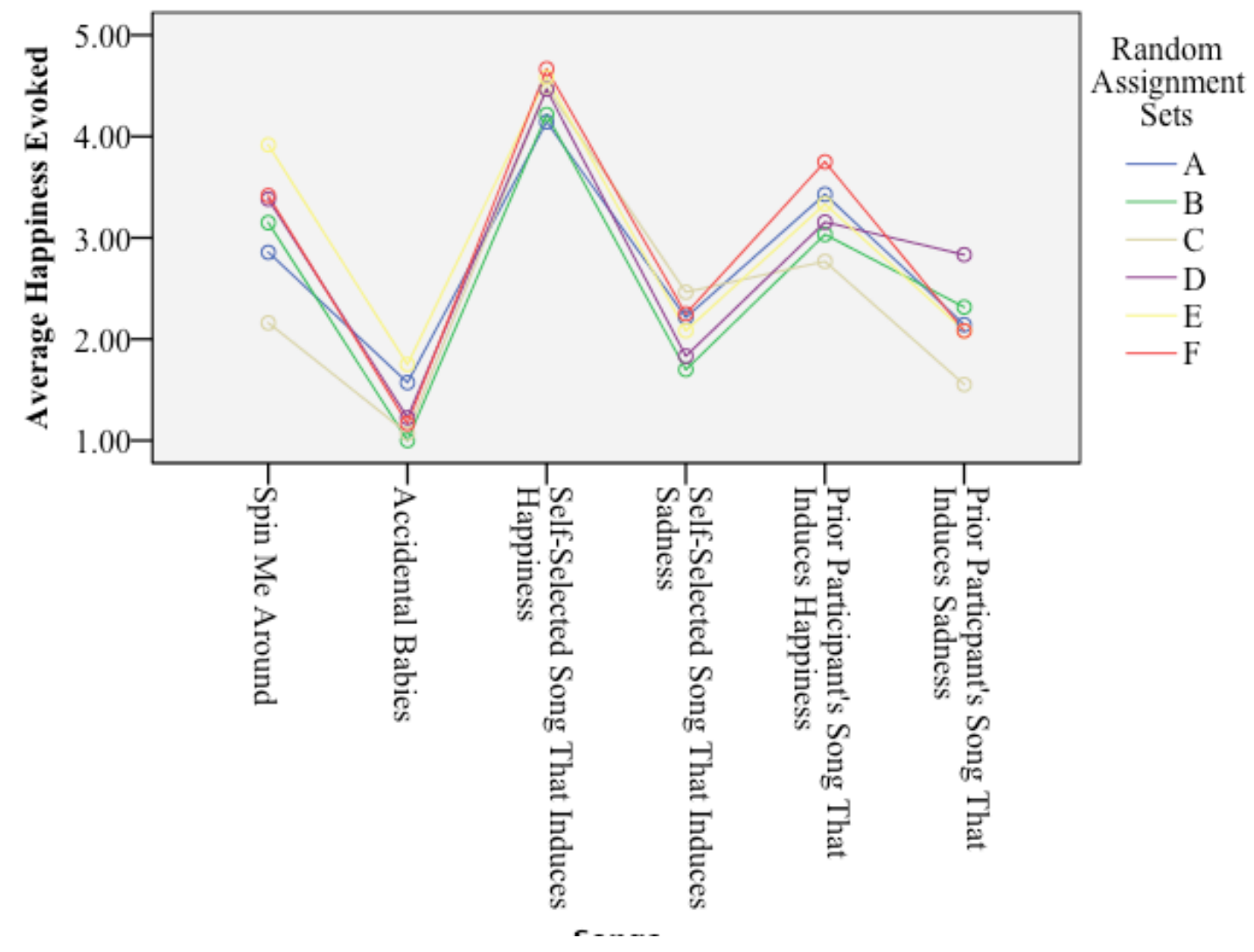

Figure 11. Song type by random assignment set on happiness. Spin Me Around had lower happiness scores in set $\mathrm{C}$ than it did in all other sets but Set $\mathrm{A}$.

Figure 11 visually depicts the means for sadness in the three-way interaction. For sadness scores, the self-selected songs that induced happiness had higher sadness scores in Set A than in the other sets $(p s \leq .03)$ except Set C. In Set A, the self-selected song that induced happiness was the second song and directly after their self-selected song that induced sadness. In Set C, the self-selected song that induced happiness was the third 
song and directly after the two prior participant's songs. The four-way interaction among the emotion, the songs, the AIMS test placement, and the random assignment sets was not statistically significant, Wilk's $\Lambda=.72, F(25,202.10)=.75, p=.80, \eta_{\mathrm{p}}{ }^{2}=.06$.

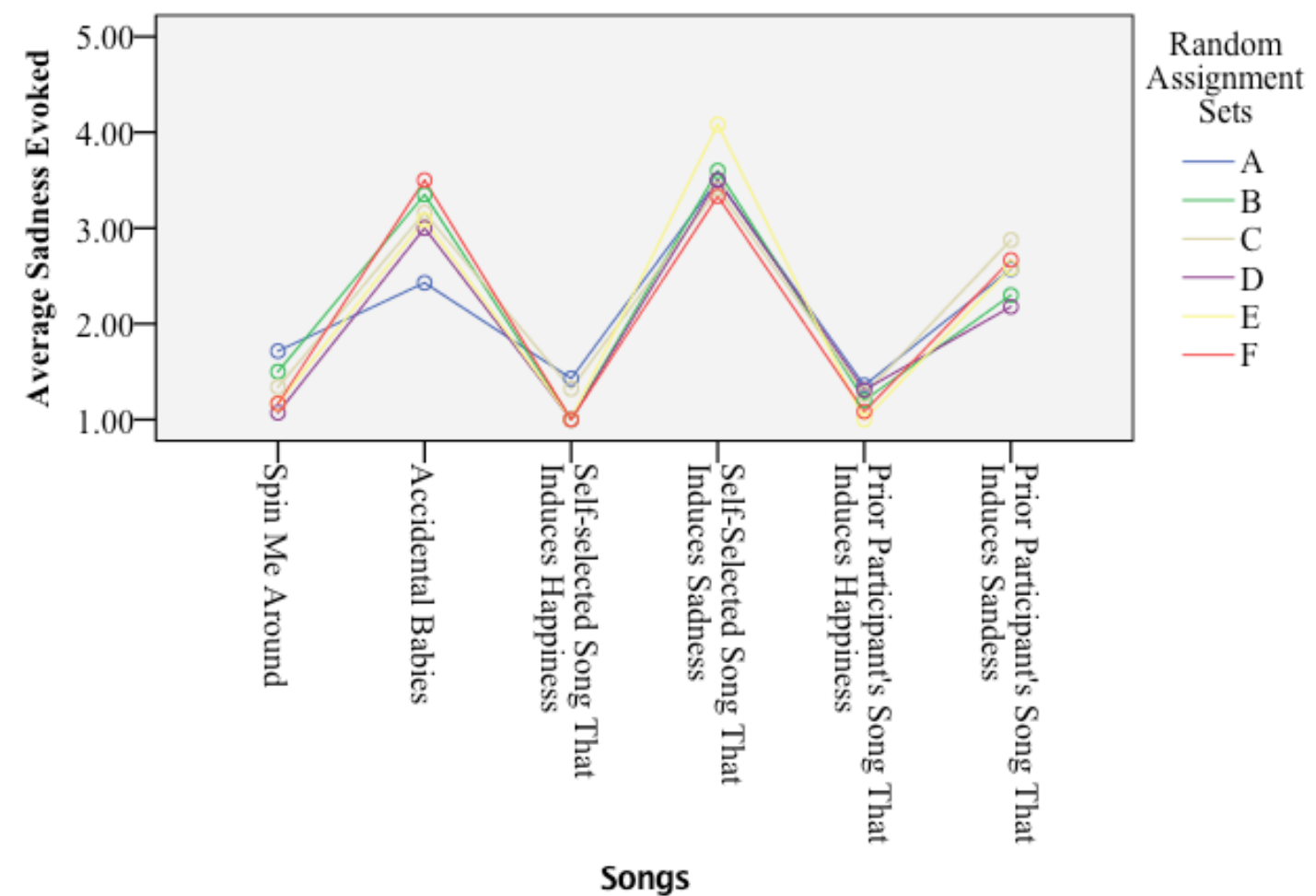

Figure 12. Song type by random assignment set on sadness. The self-selected songs that induced happiness had higher sadness scores in Set A than in the other sets except Set C.

\section{Communion}

A 6 (Between: Random assignment sets) x 6 (Within: Songs) x 2 (Between:

AIMS test placement) mixed-design ANOVA only found a significant effect among the six songs, Greenhouse-Geisser $\varepsilon=.86, F(4.33,172.16)=46.14, p<.001, \eta_{\mathrm{p}}{ }^{2}=.44$. The self-selected songs had higher communion scores than the other for songs $(p s<.001)$ but 
were similar to each other, $p=1.00$. Spin Me Around had higher scores than Accidental Babies, $p s=.04$, but all other comparisons were not statistically significant. The following table shows the means and standard errors.

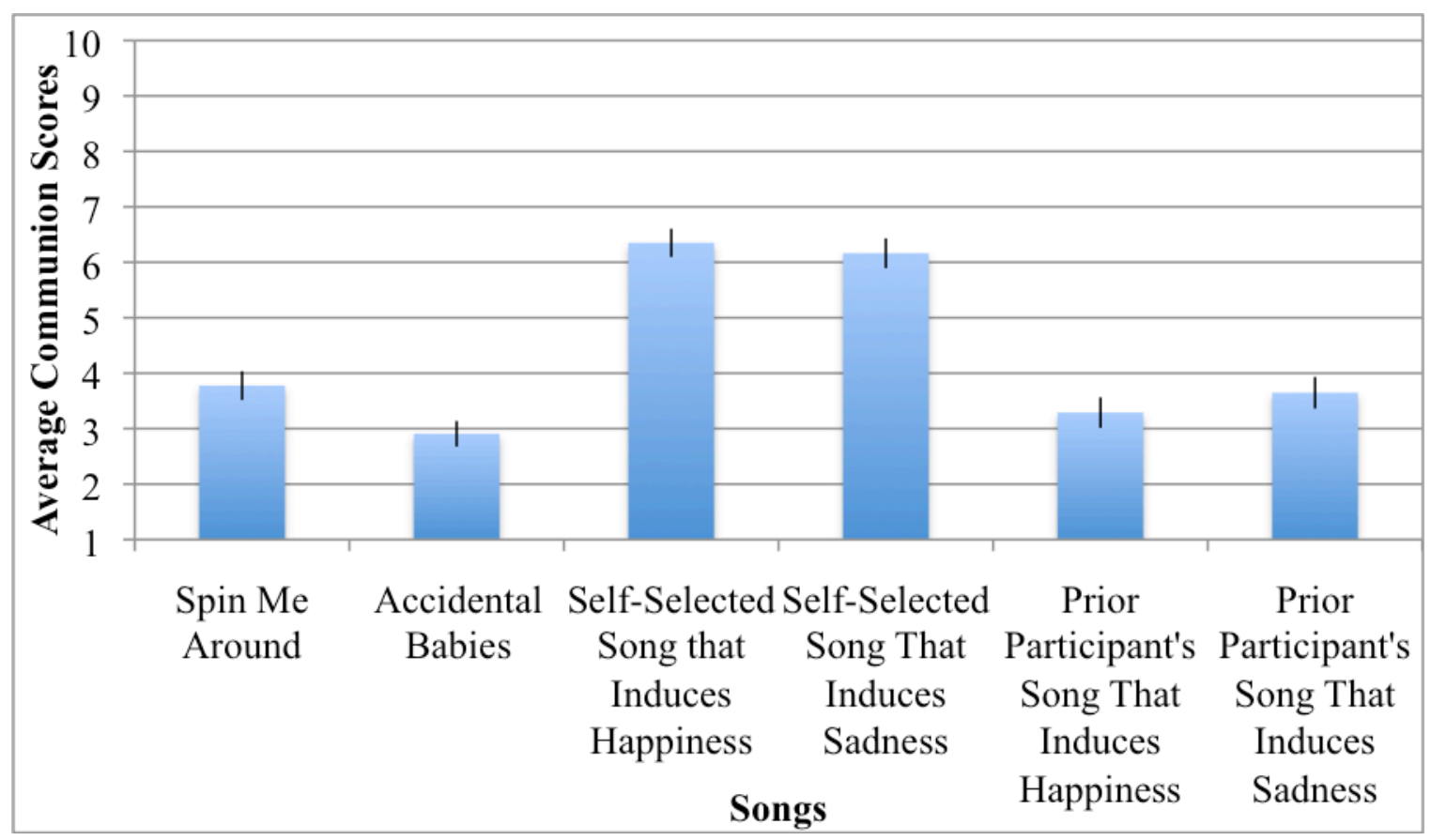

Figure 13. Song type on communion. Self-selected songs had higher communion scores than the other song types. Spin Me Around had higher communion scores than Accidental Babies.

The random assignment sets did not affect communion, $F(5,58)=1.22, p=.31$, $\eta_{\mathrm{p}}{ }^{2}=.10$. The AIMS test placement did not significantly affect communion $(F[1,58]=$ $\left.1.22, p=.93, \eta_{\mathrm{p}}^{2}<.01\right)$, and neither did the interaction between the random assignment sets and the AIMS test placement, $F(5,58)=2.02, p=.09, \eta_{\mathrm{p}}{ }^{2}=.15$. The interactions between the songs and the random assignment sets (Wilk's $\Lambda=.58, F[25,202.10)=1.28$, $\left.p=.18, \eta_{\mathrm{p}}{ }^{2}=.10\right)$ and between the songs and the AIMS test placement (Wilk's $\Lambda=.91$, $\left.F(5,54)=1.03, p=.41, \eta_{\mathrm{p}}{ }^{2}=.09\right)$ did not affect communion. Finally, the three-way interaction among the songs, the random assignment sets, and the AIMS test placement 
did not significantly affect communion scores, Wilk's $\Lambda=.66, F(25,202.10)=.97, p=$ $.50, \eta_{\mathrm{p}}^{2}=.08$.

\section{Liking}

A 6 (Between: Random assignment sets) x 6 (Within: Songs) x 2 (Between:

AIMS test placement) mixed-design ANOVA only found a significant effect among the six songs, Greenhouse-Geisser $\varepsilon=.78, F(3.91,344.94)=106.54, p<.001, \eta_{\mathrm{p}}{ }^{2}=.65$. The self-selected song that induced happiness was liked more than all of the other songs ( $p s<$ .001). The self-selected song that induced sadness was also liked more than the other songs ( $p s<.001$ ), except the participants liked it less than the self-selected song that induces happiness, $p=.003$. The participants liked Spin Me Around more than Accidental Babies $(p<.001)$ but similarly as both prior participant's songs, $p=1.00$. The participants also liked Accidental Babies less than the prior participants' songs than induced happiness, $p<.001$. All other comparisons were not statistically significant. 


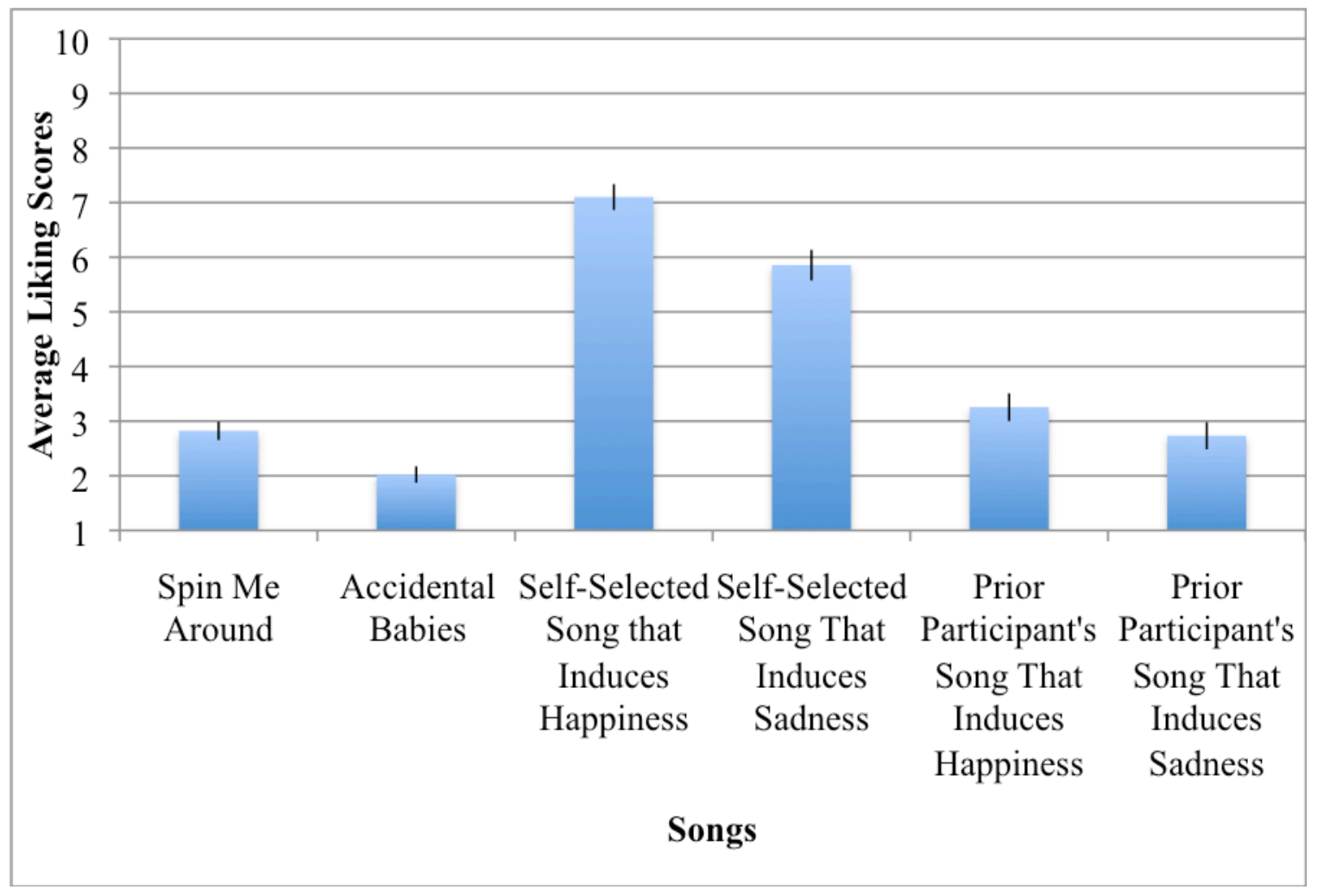

Figure 14. Song type on liking. The participants liked the self-selected songs more than the other songs.

The random assignment sets $\left(F[5,58]=.88, p=.50, \eta_{\mathrm{p}}{ }^{2}=.07\right)$ and the AIMS test placement $\left(F[1,58]=1.30, p=.26, \eta_{\mathrm{p}}{ }^{2}=.02\right)$ did not affect liking. Also, the interactions between the random assignment sets and the AIMS test places $(F[5.58]=.74, p=.60$, $\eta_{\mathrm{p}}^{2}=.06$ ), between the songs and the random assignment sets (Wilk's $\Lambda=.65, F[25$, 202.10] $\left.=.99, p=.48, \eta_{\mathrm{p}}{ }^{2}=.08\right)$, and between the songs and the AIMS test placement (Wilk's $\Lambda=.97, F[5,54]=1.07 . p=.86, \eta_{\mathrm{p}}{ }^{2}=.03$ ) did not significantly affect liking. Finally, the four-way interaction among the songs, the random assignment sets, and the AIMS test placement was not statistically significant, Wilk's $\Lambda=.63, F(25,202.10)=$ $1.07, p=.38, \eta_{\mathrm{p}}^{2}=.09$ 


\begin{abstract}
Absorption
A 2 (Aims test placement) x 6 (Random assignment set) between-subjects ANOVA showed that absorption did not change based on the manipulation. The AIMS test placement of either pre-songs $(M=118.49, S E=2.65)$ or post-songs $(M=123.95, S E$ $=2.58)$ did not significantly influence absorption scores, $F(1,66)=2.17, p=.14, \eta_{\mathrm{p}}{ }^{2}=$ .03. The random assignment sets also did not affect the absorption scores, $F(5,66)=$ $1.01, p=.42, \eta_{\mathrm{p}}{ }^{2}=.07$. The interaction between the AIMS test placement and the random assignment sets also did not affect absorption scores, $F(5,66)=1.58, p=.18, \eta_{\mathrm{p}}{ }^{2}$ $=.11$.
\end{abstract}

\title{
Primary Analyses
}

\section{Is There a Difference in Communion among the Songs?}

A 3 (Familiarity: familiar, unfamiliar, and prior-participant) x 2 (Induced Emotion: Happiness and Sadness) repeated-measures ANOVA was run. This test addressed the hypothesis that addressed the first hypothesis that familiar songs would have higher communion scores than unfamiliar songs but that communion would not differ between the songs that induced happiness and songs that induced sadness. This analysis differs from the above analysis on communion because the above analysis determined if the random assignment affect communion, and this test determined if only the hypothesized variable affected communion.

The significant main effect for familiarity (Wilk's $\Lambda=.23, F[2,66]=111.98, p<$ $\left..001, \eta^{2}=.77\right)$ showed that the familiar songs $(M=6.22, S E=.20)$ had higher communion scores than the unfamiliar $(M=3.28 S E=.21)$ and prior-participant songs $(M=3.46, S E=.21), p s<.001$. The prior-participant and unfamiliar songs had similar 
communion scores, $p=.85$. The significant main effect for induced emotion (Wilk's $\Lambda=$ $\left..93, F[1,67]=5.32, p=.02, \eta^{2}=.07\right)$ showed that the songs that induced happiness $(M=$ $4.54, S E=.20)$ induced higher communion scores than the songs that induced sadness ( $M$ $=4.09, S E=.18), p=.04$. The ANOVA also showed that there was a significant interaction between familiarity and emotion, Wilk's $\Lambda=.86, F(2,66)=5.24, p=.008, \eta^{2}$ $=.14$. Communion scores were higher for the unfamiliar song that induced happiness than they were fore the unfamiliar song that induced sadness, $p<.001$. Communion scores did not significantly differ among the songs that induced happiness and songs than induce sadness for the familiar songs nor the prior-participant songs, $p \geq .43$. These results suggest that Levinson's (1997) reward of communion was supported.

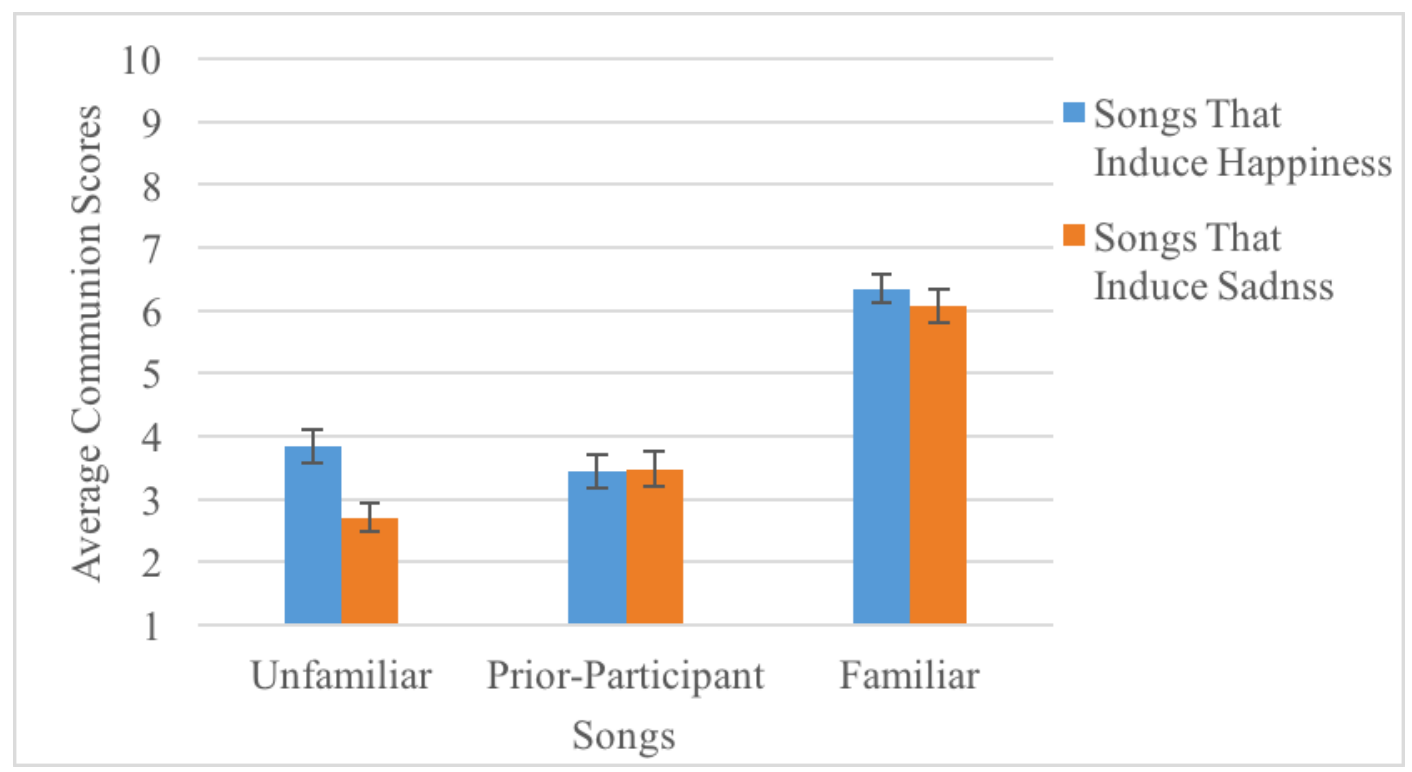

Figure 15. Familiarity on communion. Familiar songs had higher communion scores than the other song types. The unfamiliar song that induced happiness had higher communion scores that the unfamiliar songs that induced sadness.

\section{Do Happiness and Sadness Mediate the Song's Effect of Influencing Communion?}

To test the mediation process, Judd, Kenny, and McClelland's (2001) guidelines were used. Difference scores (familiar song minus the unfamiliar song) were calculated. 
Summed scores (familiar song plus unfamiliar song) were also calculated. These two variables predicted the difference in communion (familiar song minus the unfamiliar song). For happiness, this pattern was followed for the familiar song that induced happiness and the unfamiliar song that induced happiness (Spin Me Around by Patent Pending). For sadness, this pattern was followed for the familiar song that induced sadness and the unfamiliar song that induced sadness (Accidental Babies by Damien Rice). This pattern was also followed for the differences in the prior-participant and unfamiliar songs and separated for happiness and sadness. All analyses were run separately.

Happiness. For happiness, the difference in happiness scores between the familiar and unfamiliar songs did not significantly predict the difference in communion, $\beta=.19$, $t(70)=1.52, p=.13$. The summed scores significantly, negatively predicted the difference in communion scores, $\beta=-.30, t(70)=-2.36, p=.02$. These variables significantly explained $19 \%$ of the variance, $F(2,70)=7.98, p=.001$. 


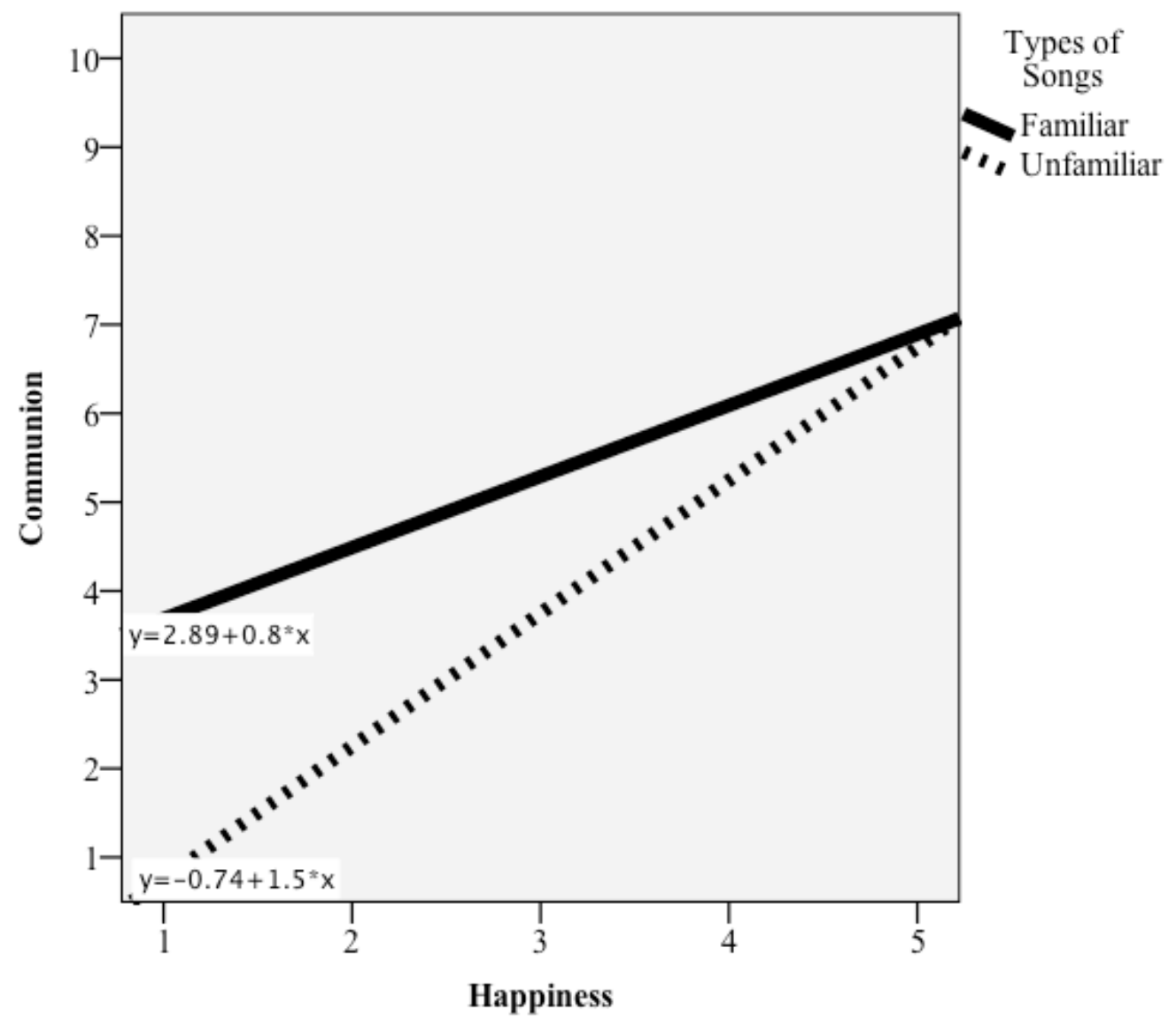

Figure 16. Happiness by familiarity on communion. Happiness in unfamiliar songs had a stronger slope than happiness from a familiar song.

The difference in happiness scores between the prior-participant songs that induced happiness and the unfamiliar songs that induced happiness significantly positively predicted the difference in communion scores between the prior-participant song that induced happiness and the unfamiliar song that induced happiness, $\beta=.53$, $t(72)=5.29, p<.001$. The sum of the happiness scores did not significantly predict the difference in communion scores, $\beta=-.08, t(72)=-.79, p=.43$. These variables explained a significant portion of the variance, $R^{2}=.29, F(2,72)=14.44, p<.001$. 
Sadness. For sadness between the familiar and unfamiliar songs, the difference in sadness scores significantly, positively predicted the difference in communion scores, $\beta=$ $.31, t(75)=2.87, p=.005$. The summed scores did not significantly predict the difference in communication scores, $\beta=.14, t(75)=1.24, p=.22$. They significantly explained $11 \%$ of the variance, $F(2,75)=4.58 p=.01$.

The difference in sadness between the prior-participant songs and the unfamiliar songs that induced sadness significantly positively predicted the difference in communion between unfamiliar song that induced sadness, $\beta=.25, t(75)=2.34, p=.02$. The summed sadness scores also positively predicted the difference in communion scores, $\beta=.28$, $t(75)=2.60, p=.01$. They significantly explained $13 \%$ of the variance, $F(2,75)=5.70, p$ $=.005$.

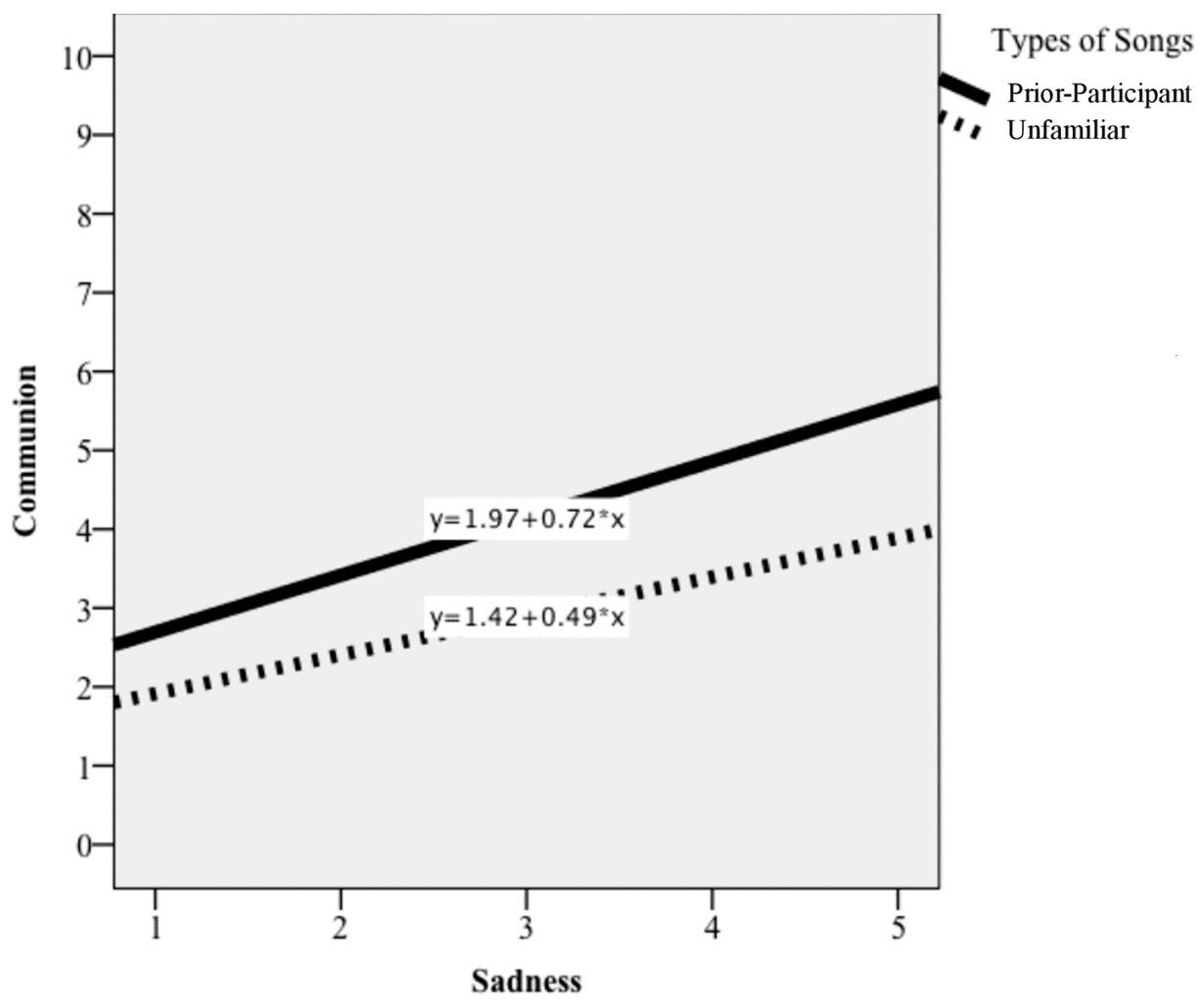

Figure 17. Sadness and limited familiarity on communion. Happiness from priorparticipant songs predicted communion more strongly than unfamiliar songs. 
These results that implied that happiness did not mediate the effect that the familiar song had on increasing communion, but it did for the unfamiliar songs. Familiarity was a moderator with happiness on communion. The more happiness the participants felt from the unfamiliar song, the more likely they were to have higher communion scores, but this relation was less for the familiar song. These results did not support Levinson's (1997) theory.

Sadness was a mediator between the song and communion for the familiar and unfamiliar songs, and this result supports Levinson (1997). For the prior-participant songs, communion increased as sadness increased slightly more strongly than for the unfamiliar song.

\section{Does Satisfaction Moderate Evoked Happiness's and Sadness's Effect on Liking a Song?}

To test these hypotheses, the difference in emotion scores (familiar song minus the unfamiliar song) and the difference in satisfaction scores (familiar song minus the unfamiliar song), and the interaction between satisfaction and the emotions (difference in emotion scores multiplied by the difference in satisfaction scores) were created to predict the difference in liking scores (familiar song minus the unfamiliar song). The regression for happiness used the familiar song that induced happiness and the unfamiliar song that induced happiness (Spin Me Around by Accidental Babies). The regression for sadness used the familiar song that induced sadness and the unfamiliar song that induced sadness (Accidental Babies by Damien Rice). Separate analyses were run for happiness and sadness. This same pattern was also used to analyze the prior-participant songs minus the unfamiliar songs. 
Happiness. After removing one outlier, the difference in happiness between the familiar and unfamiliar songs significantly, positively predicted the difference in liking between the familiar and unfamiliar songs, $\beta=.34, t(66)=3.01, p=.004$. Satisfaction did not predict liking, $\beta=.11, t(66)=.95, p=.35$. These variables significantly explained $13 \%$ of the variance, $F(2,66)=5.06, p=.009$. The interaction between happiness and satisfaction did not significantly predict liking, $\Delta R^{2}=.04, \beta=.32, t(65)=1.66, p=.10$.

The difference in happiness scores between the prior-participant songs and the unfamiliar song that induced happiness did not significantly predict the difference in liking scores between the same conditions, $\beta=.12, t(72)=1.44, p=.15$. The difference in satisfaction scores, however, did significantly, positively predict the difference in liking scores, $\beta=.67, t(72)=7.77, p<.001$. These variables explained a significant portion of the variance, $R^{2}=.47, F(2,72)=31.62, p<.001$. The interaction in Step 2 did not significantly predict liking scores, $\Delta R^{2}=.00, \beta=-.05, t(71)=-.57, p=.57$.

Sadness. For the difference between the familiar and unfamiliar songs, there were no outliers. Sadness did not significantly predict liking, $b=.17, t(75)=1.71, p=.09$. Satisfaction significantly, positively predicted liking, $b=.49, t(75)=5.05, p<.001$. These variables significantly explained $29 \%$ of the variance, $F(2,75)=15.54, p<.001$. The interaction between sadness and satisfaction did not significantly predict liking, $\Delta R^{2}$ $=.004, b=.10, t(74)=.66, p=.51$.

Sadness between the prior-participant and unfamiliar songs did not predict liking, $\beta=.03, t(74)=.36, p=.72$. Satisfaction significantly, positively predicted liking. They explained a significant portion of the variance, $R^{2}=.44, F(2,74)=28.78, p<.001$. The 
interaction in Step 2 significantly, positively predicted liking. No significant relation between liking and sadness for either low satisfaction $(b=-.29, t[73]=-1.62, p=.11)$ or average satisfaction existed, $b=.04, t(73)=.34, p=.73$. As sadness increased, so did liking for people with a relatively high amount of satisfaction, $b=.38, t(73)=2.12, p=$ .04 .

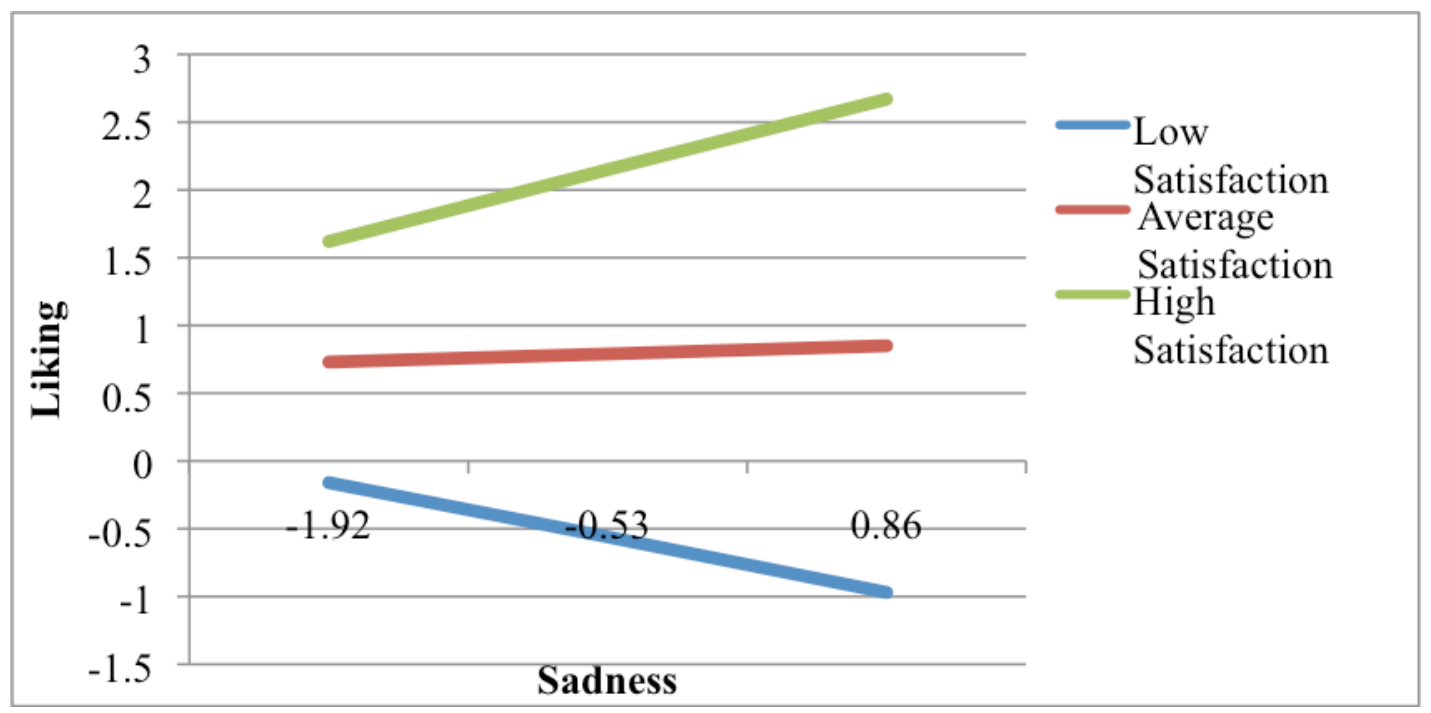

Figure 18. Sadness by satisfaction interaction on liking for unfamiliar songs. For people with high satisfaction, liking increased sadness increase. No significant relation existed for average or low satisfaction.

For familiar songs, liking increased as happiness increased. For unfamiliar songs, however, liking increased as satisfaction increased. The results of the songs that induced sadness showed different effects. Liking increased as satisfaction increased for familiar and unfamiliar songs that induced sadness. For unfamiliar songs that induced sadness, the interaction was opposite to what Hogue (2013) found. These results do not support Levinson (1997) but do show that satisfaction is important to liking songs that induce sadness. 


\section{Is Absorption a Moderator in Inducing Emotion and Communion from the Songs?}

Happiness. Absorption did not significantly predict the difference in happiness scores between the familiar songs and the unfamiliar song that induces happiness, $R^{2}=$ $.07, \beta=.07 t(69)=.56, p=.58$. It also did not predict the difference in happiness between the prior-participant song that induced happiness and the unfamiliar song that induced happiness, $R^{2}=.02, b=-.02, t(73)=-.13, p=.90$.

Sadness. Absorption also was not a significant predictor of the difference in sadness scores between the familiar song that induced sadness and the unfamiliar song that induces sadness $\left(R^{2}=.04, \beta=.21, t[76]=1.86, p=.07\right)$ or between prior-participant song that induced sadness and the unfamiliar song that induced sadness, $R^{2}=.002, \beta=$ $.04, t(76)=.38, p=.70$.

Communion in songs that induced happiness. For communion, absorption did not significantly predict the difference in communion scores between the familiar song that induced happiness and the unfamiliar song that induced happiness $\left(R^{2}=.01, \beta=.08\right.$, $t[70]=.78, p=.50)$ or for the difference between the prior-participant song that induced happiness and the unfamiliar song that induces happiness, $R^{2}=.00, \beta=-.05, t(73)=-.39$, $p=.70$.

Communion in songs that induced sadness. Absorption also did not significantly predict difference in communication between the familiar song that induced sadness and the unfamiliar song that induces sadness $\left(R^{2}=.02, \beta=.15, t[76]=1.31, p=\right.$ .20) nor did it significantly predict the difference in communication between the priorparticpant song that induced sadness and the unfamiliar song that induced sadness, $R^{2}=$ $.00, \beta=-.004, t(76)=-.04, p=.97$. 
All of these results indicated that absorption was not a moderator in inducing emotions or communion among the songs. These results did not support Levinson's (1997) theory. 


\section{CHAPTER V \\ DISCUSSION}

\section{Connection to the Hypotheses}

\section{Do Songs that Induce Sadness Influence Communion?}

This experiment hypothesized that communion would be highest for the familiar songs and lowest for the unfamiliar songs, and that people's communion with the song would be similar in songs that induced sadness as it would for songs that induced happiness. The results supported these hypotheses, as communion was higher in the familiar songs than it was in the unfamiliar songs and prior-participant songs. The results also showed that communion was similar in songs that induce sadness and songs that induce happiness in the familiar songs but not in the unfamiliar songs, where the unfamiliar song that induced happiness had higher communion that the song that induced sadness.

Hogue (2013) found that communion did not change among the musical excerpts that induced happiness, that induced sadness, or that was a neutral condition. The results from the current experiment did not support Hogue's findings. They do, however, support Levinson (1997).

The finding that the participants had stronger communion with the familiar songs than they did with the unfamiliar songs supports Levinson's (1997) idea that familiarity is 
a precursor to experiencing a reward from listening to songs that induce sadness. The findings that communion with the song was similar between the familiar song that induced sadness and the familiar song that induced happiness but that both were much higher than the unfamiliar and prior-participant songs supported Levinson, as well. These results indicated that people could receive a reward from listening to songs that induce sadness, and that this reward could be just as strong as listening to a song that induces happiness.

\section{Do the Evoked Emotions Mediate the Song's Effect on Influencing Communion?}

This experiment also hypothesized that both happiness and sadness would mediate the effect that the song had on the listener's communion. This mediation was expected for the familiar songs but not the unfamiliar songs. This experiment found that happiness did not mediate the effect of the song on producing communion. Familiarity, however, was a moderator on happiness, where the effect of happiness was much stronger on communion in the unfamiliar song that it was on the familiar song. These results did not support the hypotheses.

Hogue (2013) found that happiness mediated the effect of the song to influence communion. The results from this experiment contradicted Hogue's finding. The finding from this experiment also did not support Levinson 's (1997) idea that happiness could be a mediator between the song and the listener's communion.

Sadness was a mediator for the familiar and unfamiliar songs that induced sadness. In other words, these songs induced sadness, and as the sadness increased, so did the listener's communion with the song. This effect was slightly stronger for the prior- 
participant songs than it was for the unfamiliar songs. These results did support the hypotheses.

Hogue (2013) found that sadness was not a mediator. The results from the current experiment contradicted Hogue's findings. These findings do, however, support Levinson's (1997) statements that the song could induce sadness, and that the sadness could bring about the hedonic reward of communion. As sadness predicted communion for the unfamiliar, prior-participant, and familiar songs, familiarity was not a precursor for this mediation process, which did not support Levinson.

\section{Does Satisfaction Moderate Evoked Emotions' Effect on Liking a Song?}

It was hypothesized that regardless of the emotional content of the song, people with high satisfaction after listening to the song would like the song more than people with low satisfaction but would decrease their liking of the song as the emotion increased. People with low satisfaction would neither increase nor decrease liking as the intensity of the emotion increased.

For songs that induced happiness, the results from this experiment indicated that satisfaction did not predict liking the familiar songs. However, as satisfaction increased in unfamiliar songs, so did liking. As happiness increased in the familiar songs, so did liking, but no such relation existed in the unfamiliar songs. Because satisfaction did not moderate the effect that happiness had on liking the songs, regardless of familiarity, these results did not support the hypothesis.

Hogue (2013) found that happiness did not predict liking unfamiliar instrumental excerpts, but that liking increased as satisfaction increased. Satisfaction did not moderate the effect of happiness on liking the instrumental excerpts. The results from the current 
experiment's unfamiliar songs support Hogue's findings, but the results from the familiar songs contradict Hogue's findings.

As a result, these results did not support Levinson's (1997) theory that familiarity would be a precursor for satisfaction to influence liking. These results did suggest that emotion of happiness was important to liking the familiar songs, which supported Levinson. However, the overall concept of savoring feeling was not supported for happiness or either familiar or unfamiliar songs, because satisfaction did not interact with happiness.

For the songs that induced sadness, liking increased as sadness increased for the familiar and unfamiliar songs. Satisfaction was not related to liking the songs regardless of familiarity. Also, satisfaction only moderated the effect that sadness had on liking for the unfamiliar songs, but it was opposite to the hypothesis. For people who had relatively higher amounts of satisfaction, liking increased as sadness increased, but liking was not related to sadness for people who had relatively lower amounts of satisfaction. No such interaction existed for the familiar songs. These results did not support the hypotheses.

Hogue (2013) found that for the unfamiliar instrumental excerpts that induced sadness, the emotion of sadness did not predict liking, but satisfaction did. Satisfaction also moderated sadness, where people with relatively high satisfaction liked the unfamiliar instrumental excerpt less as sadness increased. In the current experiment, liking increased as sadness increased for people with a relatively high amount of satisfaction. The effect of satisfaction on liking in the unfamiliar songs was the opposite of Hogue's (2013) findings. 
Interestingly, these results supported Levinson's (1997) writings that people can like a song more as their sadness increases, but it did not support Levinson's idea that satisfaction would be important to familiar songs. In one sense, the interaction in the unfamiliar songs from the current study did support Levinson's savoring feelings. They showed that people could be satisfied after listening to songs that induced sadness, and that the people with relatively high amounts of satisfaction and higher amounts of sadness liked the songs the most. In another sense, savoring feeling was not supported, because Levinson qualified this phenomenon by stating that people would only like the songs if the sadness as not too intense. In people with relatively higher amounts of satisfaction liking increased as sadness increased compared to people with relatively lower amount of satisfaction. Therefore, savoring feeling was not supported in this experiment.

\section{Does Absorbing Oneself into the Songs Moderate the Effect of the Songs on Inducing Emotion and Communion?}

For the current experiment, it was hypothesized that absorption would influence communion and the induced emotions between the familiarity of the songs. Higher levels of communion for familiar songs were expected with higher levels of absorption but not for unfamiliar songs. The results from this experiment, however, showed that absorption was not related to communion based on the familiarity of the songs. Therefore, this hypothesis was not supported.

Hogue (2013) also did not find a significant relation between absorption and the emotion content of the song. Therefore, by combining Hogue's findings with the current 
findings, communion may not be a function of how well people can absorb themselves into the music. These findings did not support Levinson (1997).

It was also hypothesized that people with a stronger ability to absorb in the music would have stronger emotions (e.g., happiness and sadness) in the familiar songs than in the unfamiliar songs. Absorption did not significantly predict happiness or sadness differently in the familiar songs than it did in the unfamiliar songs. These results did not support the hypothesis.

These results do, however, support Hogue (2013), who also found that absorption did not predict the difference in emotion scores between the unfamiliar instrumental excerpt that induce happiness and the unfamiliar instrumental neutral excerpt or between the excerpt that induced sadness and the neutral excerpt. Therefore, similar to communion, absorption may not be a moderator of types of songs on influencing the strength of emotions.

It should be noted at this point that the results showed how absorption did not interact with the different types of songs and excerpts. Absorption may be a significant predictor for communion and emotions on its own. Past research has shown that absorption is a predictor of liking songs that induce sadness (Garrido \& Schubert, 2013; Hogue, Crimmins, \& Kahn, 2015) and on liking songs that induce happiness (Hogue et al., 2015). Furthermore, absorption was significantly, positively correlated with all three unfamiliar instrumental excerpts in Hogue (2013) and with three of the six song types in the current experiment. Therefore, absorption my still influence communion

The correlations among absorption and happiness and sadness show a slightly different picture. For Hogue (2013), absorption only correlated with happiness from the 
unfamiliar instrumental excerpt that induced happiness. For the current experiment, absorption was only correlated with sadness in the unfamiliar song that induced happiness and the familiar song that induced sadness. Therefore, absorption may not be related to the strength of the emotion induced by the song.

\section{Differences with Past Research}

One major difference between this experiment and Hogue (2013) was that complete songs with lyrics were used instead of nonlyrical, instrumental excerpts. Compared to instrumental background music, songs with neutral but not prosocial lyrics played to call-center customers produced customers with lower amounts of anger and employees with lower exhaustion levels (Niven, 2015). Lyrics in "gangsta rap" songs caused participants to have stronger beliefs that men and women were adversaries than the same songs without the lyrics (Wester, Crown, Quatman, \& Heesacker, 1997). Also, instrumental music that had lyrics added to it lessened the strength of the emotions in songs that induced happiness but increased the strength of the emotions in music that induced sadness (Ali \& Peynircioglu, 2006). Therefore, just the addition of lyrics to the songs could have influenced the results.

Another major difference between the current experiment and Hogue (2013) was the use of familiar and unfamiliar songs rather than strictly unfamiliar excerpts. In fact, this current experiment supported past research showing the people respond differently to familiar music than they do to unfamiliar music. For example, this experiment supported research showing that people like familiar songs more than unfamiliar songs (North \& Hargreaves, 1995), and that people like songs that induce positive emotions more than negative emotions (Witvliet \& Vrana, 2007). It also supported research showing that 
familiar songs induce stronger nonmusical outcomes (Ali \& Peynircioglu, 2010; Byron \& Fowles, 2015; Davis \& Thaut, 1989; Daynes, 2010; Tan et al., 2012), and that familiar songs induced stronger emotions (Blood and Zatorre, 2001). Therefore, the lack of support for Hogue (2013) could have been based on using familiar songs.

\section{Limitations}

One limitation with the current experiment was that the familiarity was not strictly controlled, especially for the prior-participant songs. The prior-participant songs were more familiar than the unfamiliar songs but less familiar than the familiar songs on average. However, some participants were very familiar with prior-participant songs and other people had never heard these songs. These prior-participant songs were used in the next participant's session, because they controlled for the use of their self-selected songs. The prior-participant songs allowed the data to show what happened when someone else listened to the self-selected songs. Unfortunately, using one participant's familiar songs in another participant's session was a random process, as the other participant might not have liked the genre, the content of the lyrics, or the fact that he or she did not know it.

\section{Implications}

\section{Clinical Applications}

Thaut and Davis (1993) stated that music therapists should have their clients choose their own music based on their personal preferences to decrease anxiety and increase relaxation. The results from the current experiment support this line of reasoning but for cognitive-emotional nonmusical outcomes instead of anxiety. These results imply that music therapists should use familiar songs, particularly songs that the participant chooses, to obtain stronger cognitive-emotional nonmusical outcomes. 
Because communion with the familiar song that induced sadness was similar to the familiar song that induced happiness, these results imply that songs that induce sadness can be effectively used in music therapy to obtain cognitive-emotional nonmusical outcomes. Therefore, music therapists could include songs that induce sadness in their sessions when deemed appropriate. Because satisfaction in the songs that induced sadness positively predicted liking but sadness did not, music therapists should consider the amount of satisfaction the client would have after listening to the song that induces sadness and only use the song if the person would feel a strong amount of satisfaction.

Another implication of these results is that choosing an unfamiliar song to which the client would listen was just as ineffective as randomly assigning a song to which the client would listen. These results imply that familiar songs obtain the strongest cognitiveemotional nonmusical outcomes. This implication poses a problem for group music therapy, where a song might be familiar for one client but not familiar for another. In this case, a song that was unfamiliar but induced happiness would garner the most beneficial results.

\section{Future Research}

To correct the uncertainty with the prior-participant songs, future research should have stronger controls for familiarity. For example, future research could present the participants with a list of songs and have the participants rate songs with which they are unfamiliar, familiar, or from another participant.

The analyses of the familiar songs showed that songs that induced sadness were similar in modal composition to songs that induced happiness: more songs had a major 
modality than a minor modality. These findings contradict the empirical literature showing that songs that induce sadness have a slow tempo in a minor modality (Hunter, Shellenberg, \& Schimack, 2008, 2010; Krumhansl, 2002; Larsen \& Stastny, 2011; Lundqvist, Carlsson, Hilmersson, \& Juslin, 2009; Webster \& Weir, 2005). The results from the current experiment showed that the familiar songs that induced sadness had slower tempos than the songs that induced happiness did,. These results, however, support the past research showing that songs that induce sadness have slower tempos than songs that induce happiness (Hunter et al., 2008, 2010; Larsen \& Stastny, 2011; Webster $\&$ Weir, 2005). One main difference between the current study and the past research is that the current study asked the participants what songs made them happy and sad, while the past research used unfamiliar excerpts. Future research should ask what songs make people happy and sad and determine the ecological and collative properties of those songs and how the properties differ between the emotional content of the song.

The current study found that the independent rater agreed with the participants' emotional ratings of the songs $17 \%$ of the time. It also found that when listening to a prior-participant's song that induced sadness, the participants felt equal amounts of happiness and sadness. These findings suggest that the emotional content of the songs extends beyond the collative properties of the songs, especially for songs that induce sadness. It is possible that the participants had ecological associations with the songs that helped the songs induce sadness. Therefore, future research should explore memories and social connections associated with songs that induce emotion to help identify reasons why songs induce emotions and why people like these songs. 


\section{Conclusion}

The current study supported some of Levinson's (1997) ideas of rewards from listening to songs that induce sadness. The current study supported his idea of communion with the song that induces sadness, but not that communion was a property of absorbing oneself into the song. It also supported Levinson's idea that sadness would mediate the effect of the song on inducing communion. Levinson's idea of savoring feeling was supported in one sense but not in another. Finally, the current study did not support Levinson's theory that absorbing oneself into the song would affect the reward of communion and the emotions. Overall, though, this experiment showed that people respond differently to familiar songs than they do to unfamiliar songs. 


\section{REFERENCES}

Ali, S. O., \& Peynircioglu, Z. F. (2006). Songs and emotions: Are lyrics and melodies equal partners? Psychology of Music, 34, 511 - 534.

doi:10.1177/0305735606067168

Ali, S. O., \& Peynircioglu, Z. F. (2010). Intensity of emotions conveyed and elicited by familiar and unfamiliar music. Music Perception, 27, 177-182.

doi:10.1525/mp.2010.27.3.177

Blood, A. J., \& Zatorre, R. J. (2001). Intensely pleasurable responses to music correlate with activity in brain regions implicated in reward and emotion. Proceedings of the National Academy of Sciences of the United States of America, 98, 1181811823. doi:10.1073/pnas.191355898

Bruner, G. C. (1990). Music, mood, and marketing. Journal of Marketing, 54, 94-104.

Brentar, J. E., Neuendorf, K. A., \& Armstrong, G. B. (1994). Exposure effects and affective responses to music. Communication Monographs, 61, 161-181. doi: $10.1080 / 03637759409376330$

Byron, T. P., \& Fowles, L. C. (2015). Repetition and recency increases involuntary musical imagery of previously unfamiliar songs. Psychology of Music, 43, 375 389. doi:10.1177/0305735613511506

Cohen, J. (1992). A power primer. Psychological Bulletin, 112, 155-159. doi:10.1037/0033-2909.112.1.155 
Daynes, H. (2010). Listener's perceptual and emotional responses to tonal and atonal music. Psychology of Music, 39, 468-502. doi:10.1177/0305735610378182

Davis, W. B., \& Thaut, M. H. (1989). The influence of preferred relaxing music on measures of state anxiety, relaxation, and physiological responses. Journal of Music Therapy, XXVI, 168-187. doi:10.1093/jmt/26.4.168

Garrido, S., \& Schubert, E. (2013). Adaptive and maladaptive attraction to negative emotions in music. Musicae Scientiae, 17, 147-166. doi: $10.1177 / 1029864913478305$

Holbrook, M. B., \& Schindler, R. M. (1989). Some exploratory findings on the development of musical tastes. Journal of Consumer Research, 16, 119-124. doi:10.1086/209200

Hogue, J. D. (2013). "Take a sad song and make it better": Exploring rewards related to liking unfamiliar sad music. (Master's thesis). Available from ProQuest Dissertations and Theses database. (UM No. 1552469)

Hogue, J. D., Crimmins, A. M., \& Kahn, J. H. (2015). "So sad and so slow, so why can't I turn off the radio": The effects of gender, depression, and absorption on liking music that induces sadness and music that induces happiness. Psychology of Music. Advance online publication. doi:10.1177/0305735615594489

Hunter, P. G., Schellenberg, E. G., \& Schimmack, U. (2008). Mixed affective responses to music with conflicting cues. Cognition and Emotion, 22, 327-352. doi:10.1080/02699930701438145

Hunter, P. G., Schellenberg, E. G., \& Schimack, U. (2010). Feelings and perceptions of happiness and sadness induced by music: similarities, differences, and mixed 
emotions. Psychology of Aesthetics, Creativity, and the Arts, 4, 47-56. doi:10.1037/a0016873

Ilie, G., \& Thompson, G. (2011). Experimental and cognitive changes following seven minutes exposure to music and speech. Music Perception, 28, 247-264. doi:10.1525/mp.2011.28.3.247

Judd, C. M., Kenny, D. A., \& McClelland, G. H. (2001). Estimating and testing mediation and moderation in within-subject designs. Psychological Methods, 6 , 115-134. doi:10.1037/1082-989X.6.2.115

Krumhansl, C. L. (2002). Music: A link between cognition and emotion. Current Direction in Psychological Science, 11, 45-50. doi:10.1111/1467-8721.00165

Larsen, J. T., \& Stastny, B. J. (2011). It's a bittersweet symphony: Simultaneously mixed emotional response to music with conflicting cues. Emotion, 11, 1469-1473. doi:10.1037/a0024081

Levinson, J. (1997). Music and negative emotion. In J. Robinson (Ed.) Music and meaning (pp. 215-241). Ithica, NY: Cornell University Press.

Lundqvist, L., Carlsson, F., Hilmersson, P., \& Juslin, P. (2009). Emotional responses to music: experience, expression, and physiology. Psychology of Music, 37, 61-90. doi: $10.1177 / 0305735607086048$

Montag, C., Reuter, M., \& Axmacher, N. (2011). How one's favorite song activates the reward circuitry of the brain: Personality matters! Behavioral Brain Research, 225, 511-514. doi:10.1016/j.bbr.2011.08.012 
Niven, K. (2015). Can music with prosocial lyrics heal the working world? A field intervention in a call center. Journal of Applied Social Psychology, 45, 132 - 138. doi:10.1111/jasp.12282

North, A. C., \& Hargreaves, D. J. (1995). Subjective complexity, familiarity, and liking for popular music. Psychomusicology, 14, 77-93. doi:10.1037/h0094090

Oliver, R. L. (2010). Satisfaction: A Behavioral Perspective on the Consumer. Armonk, NY: M. E. Sharpe, Inc.

Salimpoor, V. N., Benovoy, M., Larcher, K., Dagher, A., \& Zatorre, R. J. (2011). Anatomically distinct dopamine release during anticipation and experience of peak emotion to music. Nature Neuroscience, 14, 257 - 265. doi:10.1038/nn.2726

Sandstrom, G. M., \& Russo, F. A. (2011). Absorption in music: Development of a scale to identify individuals with strong emotional responses to music. Psychology of Music, 41, 216 - 228.doi:10.1177/0305735611422508

Schäfer, T., \& Sedlmeier, P. (2010). What makes us like music? Determinants of music preference. Psychology of Aesthetics, Creativity, and the Arts, 4, 223- 234. doi:10.1037/a0018374

Silverman, M. J. (2010). The effect of pitch, rhythm, and familiarity on working memory and anxiety as measured by digit recall performance. Journal of Music Therapy, 47, 70-83. doi:10.1093/jmt/47.1.70

Tan, X., Yowler, C. J., Super, D. M., \& Fratianne, R. B. (2012). The interplay of preference, familiarity, and psychosocial properties in defining relaxation music. Journal of Music Therapy, 49, 150 - 179. doi:10.1093/jmt/49.2.150

Tellegen, A., \& Atkinson, G. (1974). Openness to absorbing and self-altering experiences 
("absorption"), a trait related to hypnotic susceptibility. Journal of Abnormal Psychology, 83, 268-277. doi:10.1037/h0036681

Thaut, M. H., \& Davis, W. B. (1993). The influence of subject-selected versus experimenter-chosen music on affect, anxiety, and relaxation. Journal of Music Therapy, $X X X, 210-213$.

Vierra, A. J., \& Garrett, J. M. (2005). Understanding interobserver agreemet: The kappa statistic. Family Medicine, 37, 360 - 363.

Ward, M. K., Goodman, J. K., Irwin, J. R. (2014). The same old song: The power of familiarity in music choice. Marketing Letter, 25, 1 -11. doi:10.1007/s11002-013-9238-1

Webster, G. D., \& Weir, C. G. (2005). Emotional responses to music: Interactive effects of mode, texture, and tempo. Motivation and Emotion, 29, 19-39. doi:10.1007/s11031-005-4414-0

Wester, S. R., Crown, C. L., Quatman, G. L., \& Heesacker, M. (1997). The influence of sexually violent rap music on attitudes of men with little prior exposure. Psychology of Women Quarterly, 21, 497 - 508. doi: 10.1111/j.14716402.1997.tb00127.x

Witvliet, C. V. O., \& Vrana, S. R. (2007). Play it again Sam: Repeated exposure to emotionally evocative music polarizes liking and smiling responses, and influences other affective reports, facial EMG, and heart rate. Cognition and Emotion, 21, 3-25. doi:10.1080/02699930601000672 


\section{APPENDIX A \\ DEMOGRAPHICS QUESTIONNAIRE}

Age:

Year in College (Circle one): Freshman Sophomore Junior Senior Graduate

Gender (Circle one): Male Female

Ethnicity (Circle One): Caucasian African-American Asian Native American

Other:

Are you a musician or vocalist? Yes No

Please indicate the amount of training you have had in playing or singing music:

\begin{tabular}{|c|c|c|c|c|}
\hline None at All & A Little & Some & A Fair Amount & A lot \\
\hline 1 & 2 & 3 & 4 & 5 \\
\hline
\end{tabular}

What one genre/type of music do you listen to the most?

How important is music to you in your life?

\begin{tabular}{|c|c|c|c|c|}
\hline Not at All & A Little & Some & A Fair Amount & A lot \\
\hline 1 & 2 & 3 & 4 & 5 \\
\hline
\end{tabular}

What song makes you sad when you listen to it?

What song makes you happy when you listen to it? 
Please indicate the strength of each emotion you feel right now.

\begin{tabular}{|c|c|c|c|c|c|}
\hline Emotion & $\begin{array}{c}\text { Not Felt } \\
\text { At All }\end{array}$ & $\begin{array}{c}\text { Felt A } \\
\text { Little }\end{array}$ & $\begin{array}{c}\text { Somewhat } \\
\text { Felt }\end{array}$ & $\begin{array}{c}\text { Felt } \\
\text { Strongly }\end{array}$ & $\begin{array}{c}\text { Intensely } \\
\text { Felt Emotion }\end{array}$ \\
\hline Happiness & 1 & 2 & 3 & 4 & 5 \\
\hline Sadness & 1 & 2 & 3 & 4 & 5 \\
\hline Satisfied & 1 & 2 & 3 & 4 & 5 \\
\hline Engaged & 1 & 2 & 3 & 4 & 5 \\
\hline
\end{tabular}




\section{APPENDIX B}

\section{ABSORPTION IN MUSIC SCALE (AIMS)}

1. I will sometimes move my hand as if I were "conducting" music.

$\begin{array}{ccccc}1 & 2 & 3 & 4 & 5 \\ \begin{array}{c}\text { Strongly } \\ \text { Disagree }\end{array} & \text { Disagree } & \text { Neutral } & \text { Agree } & \begin{array}{c}\text { Strongly } \\ \text { Agree }\end{array}\end{array}$

2. When listening to music, I sometimes temporarily forget where I am.

$\begin{array}{ccccc}1 & 2 & 3 & 4 & 5 \\ \begin{array}{c}\text { Strongly } \\ \text { Disagree }\end{array} & \text { Disagree } & \text { Neutral } & \text { Agree } & \begin{array}{c}\text { Strongly } \\ \text { Agree }\end{array}\end{array}$

3. I sometimes feel like I am "one" with the music.

$\begin{array}{ccccc}1 & 2 & 3 & 4 & 5 \\ \begin{array}{c}\text { Strongly } \\ \text { Disagree }\end{array} & \text { Disagree } & \text { Neutral } & \text { Agree } & \begin{array}{c}\text { Strongly } \\ \text { Agree }\end{array}\end{array}$

4. When I listen to music I can get so caught up in it that I don't notice anything.

$\begin{array}{ccccc}1 & 2 & 3 & 4 & 5 \\ \begin{array}{c}\text { Strongly } \\ \text { Disagree }\end{array} & \text { Disagree } & \text { Neutral } & \text { Agree } & \begin{array}{c}\text { Strongly } \\ \text { Agree }\end{array}\end{array}$

5. When I feel that nobody understands me, I often turn on some music

$\begin{array}{ccccc}1 & 2 & 3 & 4 & 5 \\ \begin{array}{c}\text { Strongly } \\ \text { Disagree }\end{array} & \text { Disagree } & \text { Neutral } & \text { Agree } & \begin{array}{c}\text { Strongly } \\ \text { Agree }\end{array}\end{array}$


6. I will stop everything that I'm doing in order to listen to a special song/piece of music that is playing.

$\begin{array}{ccccc}1 & 2 & 3 & 4 & 5 \\ \text { Strongly } & \text { Disagree } & \text { Neutral } & \text { Agree } & \begin{array}{c}\text { Strongly } \\ \text { Agree }\end{array}\end{array}$

7. I can imagine a song/piece of music so vividly that it holds my attention as if I were hearing it 'live.'

$\begin{array}{ccccc}1 & 2 & 3 & 4 & 5 \\ \text { Strongly } & \text { Disagree } & \text { Neutral } & \text { Agree } & \begin{array}{c}\text { Strongly } \\ \text { Agree }\end{array}\end{array}$

8. When I hear good music I tend to lose my train of thought and forget what I was thinking about.

$\begin{array}{ccccc}1 & 2 & 3 & 4 & 5 \\ \text { Strongly } & \text { Disagree } & \text { Neutral } & \text { Agree } & \begin{array}{c}\text { Strongly } \\ \text { Agree }\end{array}\end{array}$

9. Sometimes when listening to music I feel as if my mind can understand the whole world.

\begin{tabular}{|c|c|c|c|c|}
\hline 1 & 2 & 3 & 4 & 5 \\
\hline $\begin{array}{l}\text { Strongly } \\
\text { Disagree }\end{array}$ & Disagree & Neutral & Agree & $\begin{array}{l}\text { Strongly } \\
\text { Agree }\end{array}$ \\
\hline
\end{tabular}

10. I sometimes feel that I understand the songwriter/composer's intentions completely.

$\begin{array}{ccccc}1 & 2 & 3 & 4 & 5 \\ \text { Strongly } & \text { Disagree } & \text { Neutral } & \text { Agree } & \begin{array}{c}\text { Strongly } \\ \text { Agree }\end{array}\end{array}$


11. I can change almost any sound into music by the way I listen to it.

$\begin{array}{ccccc}1 & 2 & 3 & 4 & 5 \\ \begin{array}{c}\text { Strongly } \\ \text { Disagree }\end{array} & \text { Disagree } & \text { Neutral } & \text { Agree } & \begin{array}{c}\text { Strongly } \\ \text { Agree }\end{array}\end{array}$

12. I have stopped walking to listen to music that I came across on my path.

$\begin{array}{ccccc}1 & 2 & 3 & 4 & 5 \\ \begin{array}{c}\text { Strongly } \\ \text { Disagree }\end{array} & \text { Disagree } & \text { Neutral } & \text { Agree } & \begin{array}{c}\text { Strongly } \\ \text { Agree }\end{array}\end{array}$

13. While listening to music, I may become so involved that I may forget about myself and my surroundings

$\begin{array}{ccccc}1 & 2 & 3 & 4 & 5 \\ \text { Strongly } & \text { Disagree } & \text { Neutral } & \text { Agree } & \begin{array}{c}\text { Strongly } \\ \text { Agree }\end{array}\end{array}$

14. If I want to feel creative, I will turn on some music.

$\begin{array}{ccccc}1 & 2 & 3 & 4 & 5 \\ \begin{array}{c}\text { Strongly } \\ \text { Disagree }\end{array} & \text { Disagree } & \text { Neutral } & \text { Agree } & \begin{array}{c}\text { Strongly } \\ \text { Agree }\end{array}\end{array}$

15. It is sometimes possible for me to be completely immersed in music and to feel as if my whole state of consciousness has been temporarily altered.

$\begin{array}{ccccc}1 & 2 & 3 & 4 & 5 \\ \begin{array}{c}\text { Strongly } \\ \text { Disagree }\end{array} & \text { Disagree } & \text { Neutral } & \text { Agree } & \begin{array}{c}\text { Strongly } \\ \text { Agree }\end{array}\end{array}$

16. I know what people mean when they talk about mind-altering musical experiences.
1
2
3
4
5 
Strongly $\quad$ Disagree Neutral Agree
Disagree $\quad \begin{gathered}\text { Strongly } \\ \text { Agree }\end{gathered}$

17. At times when listening to music, I feel more connected with other people.
1
2
3
4
5
Strongly
Disagree Neutral
Agree
Strongly
Disagree Disagree Neutral Agree Agree

18. I find that different sounds have different colors (e.g., red, blue).

$\begin{array}{ccccc}1 & 2 & 3 & 4 & 5 \\ \begin{array}{c}\text { Strongly } \\ \text { Disagree }\end{array} & \text { Disagree } & \text { Neutral } & \text { Agree } & \begin{array}{c}\text { Strongly } \\ \text { Agree }\end{array}\end{array}$

19. I spend as much time as I can every day listening to music.

$\begin{array}{ccccc}1 & 2 & 3 & 4 & 5 \\ \begin{array}{c}\text { Strongly } \\ \text { Disagree }\end{array} & \text { Disagree } & \text { Neutral } & \text { Agree } & \begin{array}{c}\text { Strongly } \\ \text { Agree }\end{array}\end{array}$

20. Sometimes music makes me feel and experience things as I did when I was a child.

$\begin{array}{ccccc}1 & 2 & 3 & 4 & 5 \\ \begin{array}{c}\text { Strongly } \\ \text { Disagree }\end{array} & \text { Disagree } & \text { Neutral } & \text { Agree } & \begin{array}{c}\text { Strongly } \\ \text { Agree }\end{array}\end{array}$

21. Sometimes I almost feel as if a song was written especially for/ about me.

$\begin{array}{ccccc}1 & 2 & 3 & 4 & 5 \\ \begin{array}{c}\text { Strongly } \\ \text { Disagree }\end{array} & \text { Disagree } & \text { Neutral } & \text { Agree } & \begin{array}{c}\text { Strongly } \\ \text { Agree }\end{array}\end{array}$

22. I sometimes make my movements/actions (opening doors, pushing buttons, stepping of curbs) coincide with the music.

$\begin{array}{ccccc}1 & 2 & 3 & 4 & 5 \\ \begin{array}{c}\text { Strongly } \\ \text { Disagree }\end{array} & \text { Disagree } & \text { Neutral } & \text { Agree } & \begin{array}{c}\text { Strongly } \\ \text { Agree }\end{array}\end{array}$


23. I like to find patterns in everyday sounds.

\begin{tabular}{|c|c|c|c|c|}
\hline 1 & 2 & 3 & 4 & 5 \\
\hline $\begin{array}{l}\text { Strongly } \\
\text { Disagree }\end{array}$ & Disagree & Neutral & Agree & $\begin{array}{c}\text { Strongly } \\
\text { Agree }\end{array}$ \\
\hline
\end{tabular}

24. When listening to music I can lose all sense of time.

$\begin{array}{ccccc}1 & 2 & 3 & 4 & 5 \\ \text { Strongly } & \text { Disagree } & \text { Neutral } & \text { Agree } & \begin{array}{c}\text { Strongly } \\ \text { Agree }\end{array}\end{array}$

25. Before I do an activity (e.g., exercise, study), I usually carefully consider what music to play along with it.

$\begin{array}{ccccc}1 & 2 & 3 & 4 & 5 \\ \text { Strongly } & \text { Disagree } & \text { Neutral } & \text { Agree } & \begin{array}{c}\text { Strongly } \\ \text { Agree }\end{array}\end{array}$

26. The sound of a speaking voice can be so fascinating to me that I can just go on listening to it.

$\begin{array}{ccccc}1 & 2 & 3 & 4 & 5 \\ \text { Strongly } & \text { Disagree } & \text { Neutral } & \text { Agree } & \begin{array}{c}\text { Strongly } \\ \text { Agree }\end{array}\end{array}$

27. Music sometimes helps me 'step outside' my usual self and experience an entirely different state of being.

\begin{tabular}{|c|c|c|c|c|}
\hline 1 & 2 & 3 & 4 & 5 \\
\hline $\begin{array}{l}\text { Strongly } \\
\text { Disagree }\end{array}$ & Disagree & Neutral & Agree & $\begin{array}{c}\text { Strongly } \\
\text { Agree }\end{array}$ \\
\hline
\end{tabular}

28. When listening to music, I often imagine the musicians playing the songs.

$\begin{array}{lllll}1 & 2 & 3 & 4 & 5\end{array}$




$$
\begin{array}{lll}
\text { Strongly } & \text { Disagree Neutral Agree } & \begin{array}{c}
\text { Strongly } \\
\text { Disagree }
\end{array}
\end{array}
$$

29. When listening to great music I sometimes feel as if I am being lifted into the air.

$\begin{array}{ccccc}1 & 2 & 3 & 4 & 5 \\ \text { Strongly } & \text { Disagree } & \text { Neutral } & \text { Agree } & \begin{array}{c}\text { Strongly } \\ \text { Agree }\end{array}\end{array}$

30. When I am listening to music, I can tune out everything else.

$\begin{array}{ccccc}1 & 2 & 3 & 4 & 5 \\ \begin{array}{l}\text { Strongly } \\ \text { Disagree }\end{array} & \text { Disagree } & \text { Neutral } & \text { Agree } & \begin{array}{c}\text { Strongly } \\ \text { Agree }\end{array}\end{array}$

31. I sometimes see vivid images in my head when I listen to music.

$\begin{array}{ccccc}1 & 2 & 3 & 4 & 5 \\ \begin{array}{c}\text { Strongly } \\ \text { Disagree }\end{array} & \text { Disagree } & \text { Neutral } & \text { Agree } & \begin{array}{c}\text { Strongly } \\ \text { Agree }\end{array}\end{array}$

32. I sometimes close my eyes so I can focus on the music I am listening to.

$\begin{array}{ccccc}1 & 2 & 3 & 4 & 5 \\ \text { Strongly } & \text { Disagree } & \text { Neutral } & \text { Agree } & \begin{array}{c}\text { Strongly } \\ \text { Agree }\end{array}\end{array}$

33. There are times when I will do nothing except listen to music.

$\begin{array}{ccccc}1 & 2 & 3 & 4 & 5 \\ \begin{array}{c}\text { Strongly } \\ \text { Disagree }\end{array} & \text { Disagree } & \text { Neutral } & \text { Agree } & \begin{array}{c}\text { Strongly } \\ \text { Agree }\end{array}\end{array}$

34. I sometimes feel like I'm part of something bigger than myself when I listen to music.

$\begin{array}{ccccc}1 & 2 & 3 & 4 & 5 \\ \begin{array}{c}\text { Strongly } \\ \text { Disagree }\end{array} & \text { Disagree } & \text { Neutral } & \text { Agree } & \begin{array}{c}\text { Strongly } \\ \text { Agree }\end{array}\end{array}$




\section{APPENDIX C}

\section{DEPENDENT MEASURES}

Scales

\begin{tabular}{|c|c|c|c|c|c|c|c|c|c|c|c|}
\hline & $\begin{array}{r}\text { Disagr } \\
\text { lot }\end{array}$ & & & & & & & & & & $\begin{array}{c}\text { I totally } \\
\text { agree }\end{array}$ \\
\hline I like this music. & 1 & 2 & 3 & 2 & & & & 7 & 8 & 9 & 10 \\
\hline $\begin{array}{l}\text { I could not live without this } \\
\text { music. }\end{array}$ & 1 & 2 & 3 & 2 & & & & 7 & 8 & 9 & 10 \\
\hline $\begin{array}{l}\text { I spend a lot of money to } \\
\text { purchase this music. }\end{array}$ & 1 & 2 & 3 & 2 & & & & 7 & 8 & 9 & 10 \\
\hline $\begin{array}{c}\text { I am a passionate listener of this } \\
\text { music. }\end{array}$ & 1 & 2 & 3 & 2 & & & & 7 & 8 & 9 & 10 \\
\hline $\begin{array}{l}\text { I often visit concerts or discos to } \\
\text { listen to this music. }\end{array}$ & 1 & 2 & 3 & 2 & & & & 7 & 8 & 9 & 10 \\
\hline I just need this music. & 1 & 2 & 3 & 2 & & & 6 & 7 & 8 & 9 & 10 \\
\hline
\end{tabular}




\begin{tabular}{|c|c|c|c|c|c|c|c|c|c|c|}
\hline & $\begin{array}{l}\text { agr } \\
\text { lot }\end{array}$ & & & & & & & & & $\begin{array}{c}\text { I totally } \\
\text { agree }\end{array}$ \\
\hline This music can express my personal values. & 1 & 2 & 3 & 4 & 5 & 6 & 7 & 8 & 9 & 10 \\
\hline $\begin{array}{l}\text { This music provide me with interesting or } \\
\text { important information. }\end{array}$ & 1 & 2 & 3 & 4 & 5 & 6 & 7 & 8 & 9 & 10 \\
\hline This music can express my identity. & 1 & 2 & 3 & 4 & 5 & 6 & 7 & 8 & 9 & 10 \\
\hline $\begin{array}{l}\text { This music enables me to identify with its } \\
\text { performers or artists. }\end{array}$ & 1 & 2 & 3 & 4 & 5 & 6 & 7 & 8 & 9 & 10 \\
\hline With this music, I can express my emotions & 1 & 2 & 3 & 4 & 5 & 6 & 7 & 8 & 9 & 10 \\
\hline This music helps me connect with others. & 1 & 2 & 3 & 4 & 5 & 6 & 7 & 8 & 9 & 10 \\
\hline This music can help me feel close to others. & 1 & 2 & 3 & 4 & 5 & 6 & 7 & 8 & 9 & 10 \\
\hline
\end{tabular}

\section{Memory Questions}

Did you experience a memory while listening to this song? Yes No

If yes, was this memory happy, sad, or neutral?

Happy Sad Neutral 


\section{APPENDIX D}

\section{EMOTION RESPONSE QUESTIONNAIRE}

Please rate your familiarity with this song (used in Ilie \& Thompson, 2011)

$\begin{array}{llllll}0 & 1 & 2 & 3 & 4 & 5\end{array}$

I was not familiar with it

prior to this experiment
I was very familiar with it prior to this experiment

Please indicate the strength of each emotion your felt while listening to this song.

\begin{tabular}{|c|c|c|c|c|c|}
\hline Emotion & $\begin{array}{c}\text { Not Felt } \\
\text { At All }\end{array}$ & $\begin{array}{c}\text { Felt A } \\
\text { Little }\end{array}$ & $\begin{array}{c}\text { Somewhat } \\
\text { Felt }\end{array}$ & $\begin{array}{c}\text { Felt } \\
\text { Strongly }\end{array}$ & $\begin{array}{c}\text { Intensely } \\
\text { Felt Emotion }\end{array}$ \\
\hline Happiness & 1 & 2 & 3 & 4 & 5 \\
\hline Sadness & 1 & 2 & 3 & 4 & 5 \\
\hline Satisfied & 1 & 2 & 3 & 4 & 5 \\
\hline Engaged & 1 & 2 & 3 & 4 & 5 \\
\hline
\end{tabular}

When you responded to the "satisfaction" item, what did "satisfaction" mean to you?

What is causing you to feel this amount of satisfaction?

To you, is this satisfaction different from liking the song? YES NO

Why or why not? 


\section{APPENDIX E \\ QUESTIONS FOR THE SONGS RATER}

What key is each song in?

Does the song change key? YES NO

If so, how many times and to what key(s)?

What is each song's tempo?

Does the song change tempo? YES NO

If so, how many times and to what tempo(s)?

Does the musical content convey happiness or sadness? Happiness Sadness Neither

If Neither, what emotion does it convey?

Does the lyrical content convey happiness or sadness? Happiness Sadness Neither

If Neither, what emotion does it convey?

Please provide an example of the lyrical content 